\title{
Measuring Economic Policy Uncertainty
}

\author{
Scott R. Baker ${ }^{\mathrm{a}}$, Nicholas Bloom ${ }^{\mathrm{b}}$, and Steven J. Davis ${ }^{\mathrm{c}}$
}

$1^{\text {st }}$ January 2013

\begin{abstract}
Many commentators argue that uncertainty about tax, spending, monetary and regulatory policy slowed the recovery from the 2007-2009 recession. To investigate this we develop a new index of economic policy uncertainty (EPU), built on three components: the frequency of newspaper references to economic policy uncertainty, the number of federal tax code provisions set to expire, and the extent of forecaster disagreement over future inflation and government purchases. This EPU index spikes near consequential presidential elections and major events such as the Gulf wars and the 9/11 attack. It also rises steeply from 2008 onward. We then evaluate our EPU index, first on a sample of 3,500 human audited news articles, and second against other measures of policy uncertainty, with these suggesting our EPU index is a good proxy for actual economic policy uncertainty. Drilling down into our index we find that the post-2008 increase was driven mainly by tax, spending and healthcare policy uncertainty. Finally, VAR estimates show that an innovation in policy uncertainty equal to the increase from 2006 to 2011 foreshadows declines of up to $2.3 \%$ in GDP and 2.3 million in employment.
\end{abstract}

JEL No. D80, E22, E66, G18, L50

Keywords: economic uncertainty, policy uncertainty, business cycles

Acknowledgements: We thank Matt Gentzkow, Kevin Hassett, Greg Ip, John Makin, Johannes Pfeifer, Itay Saporta, Sam Schulhofer-Wohl, Jesse Shapiro, Erik Sims, Stephen Terry and many seminar and conference audiences for comments. We thank Sophie Biffar and Kyle Kost for extensive research support, and the National Science Foundation, the Sloan Foundation and the Initiative on Global Markets and the Stigler Center for the Study of the Economy at the University of Chicago and the State for financial support.

\footnotetext{
${ }^{\text {a }}$ Stanford; srbaker@stanford.edu

${ }^{\mathrm{b}}$ Stanford, Centre for Economic Performance, CEPR and NBER; nbloom@stanford.edu

${ }^{c}$ University of Chicago Booth School of Business, NBER and AEI; steven.davis@chicagobooth.edu
} 


\section{INTRODUCTION}

In recent years, many commentators have made two claims about economic policy uncertainty. First, that it increased after the start of the 2007-2009 recession because of businesses and households uncertainty about future tax, spending, regulatory, health-care and monetary policies. Second, that this increase in policy uncertainty slowed the recovery from the recession by leading businesses and households to postpone investment, hiring and consumption expenditure.

We seek to investigate both claims. To do so, we first construct a new measure of economic policy uncertainty (EPU) and examine its evolution since $1985 .{ }^{1}$ Figure 1 plots this index of policy-related economic uncertainty. We build the index from components that measure three aspects of economic policy uncertainty: (i) the frequency of references to economic uncertainty and policy in 10 leading newspapers; (ii) the number of federal tax code provisions set to expire in future years; and (iii) the extent of disagreement among economic forecasters over future federal, state, and local government purchases and the level of the CPI. The resulting EPU index looks sensible, with spikes around consequential presidential elections and major political shocks like the Gulf Wars and 9/11. Recently, it rose to historic highs after the Lehman bankruptcy and TARP legislation, the 2010 midterm elections, the Eurozone crisis and the U.S. debt-ceiling dispute.

We evaluate this index in several ways. First, we had a team of undergraduates read a sample consisting of 3,500 newspaper articles to assess whether they actually discuss policy uncertainty. We compare our automated news-based index to the human readings, finding a good correspondence. We also compare our EPU index against the frequency of the word "uncertainty" in the Federal Open Market Committee (FOMC) Beige Book, a 15,000 word summary of the state of the economy produced before every FOMC meeting, again finding a good correspondence. Finally, we find a strong correlation between our EPU index and the number of stock-market jumps triggered by policy news. We also investigate the possibility of political slant in our news-based index of policy uncertainty and find little evidence for this. In summary, our EPU index looks like a reasonable proxy for true economic policy uncertainty.

\footnotetext{
${ }^{1}$ Our data are available on www.policyuncertainty.com
} 
Drilling down into specific policy areas using a large database on around 2,000 national and local US newspaper we find that the most common type of policy uncertainty in news articles concerns taxes, spending, monetary and regulatory policy. Interestingly, while these four areas are the largest in levels, the recent increase in policy uncertainty since 2008 was driven mainly by increases in tax, spending and regulatory (particularly healthcare) policy uncertainty. We found no evidence for an increase in monetary policy uncertainty since 2008 , suggesting that the mainstream media did not perceive monetary policy as more uncertain over this period.

Together, these pieces of evidence suggest that the first claim - that policy uncertainty increased since the onset of the 2007-2009 recession - is correct, with this increase driven primarily by uncertainty over tax, spending, and regulatory policy.

We then turn to estimating the dynamic relationship between our EPU index economic outcomes like GDP growth and employment in a simple vector autoregressive (VAR) models. The VAR results suggest that an innovation in policy uncertainty equivalent to the actual increase from 2006 to 2011 is followed by a decline of about $2.3 \%$ in GDP, $14 \%$ in investment, and of 2.3 million in employment. Peak estimated responses occur 9 to 24 months later, depending on outcome measure and specification. These results are not necessarily causal - for example, policy is forward looking so this may simply reflect policymakers acting more aggressively when they foresee an economic slowdown. However, the VAR results do show that increases in our Economic Policy Uncertainty index foreshadow sizable declines in output, investment and employment. This result is consistent with that the second claim outlined above - that policy uncertainty impeded the recovery from the 2007-2009 recession - but it is not definitive because of the inability to determine cause and effect in our VAR estimations. ${ }^{2}$

This work connects to at least two literatures. The first is the literature on the impact of general economic uncertainty on investment. The theoretical literature goes back at least to Bernanke (1983), who points out that when investment projects are expensive to cancel or workers are costly to hire and fire, high uncertainty gives firms an

\footnotetext{
${ }^{2}$ See also Stock and Watson (2011) who use our economic policy uncertainty measure to investigate the factors behind the 2007-2009 recession and slow recovery and come to a similar conclusion, that policy uncertainty is a strong candidate for explaining the poor economic performance but identifying causality is extremely hard.
} 
incentive to delay investment decisions. ${ }^{3}$ Of course, once uncertainty falls back down, firms start hiring and investing again to address pent-up demand. Other reasons for a depressing effect of uncertainty include pushing up the cost of finance (e.g., Gilchrist et al. (2010), Fernandez-Villaverde et al. (2011) and Pastor and Veronesi (2011a)) and increasing managerial risk-aversion (Panousi and Papanikolaou, 2011).

Second, there is a literature focused on policy uncertainty. A number of papers, including Friedman (1968), Rodrik (1991), Higgs (1997) and Hassett and Metcalf (1999), consider the detrimental effects that monetary, fiscal, and regulatory policy uncertainty can have on an economy. More recently, Bonn and Pfeifer (2011) and FernandezVillaverde at al. (2011) examine the impact of policy uncertainty in a stochastic DSGE model, finding moderately negative impacts, while Pastor and Veronesi (2011a,b) theoretically model the links between the business cycle, policy uncertainty, and stock market volatility. Empirical papers on policy uncertainty include Julio and Yook (2010), who find that corporate investment falls around national elections, Durnev (2010) who finds that corporate investment is 40 percent less sensitive to stock-prices in election years, Brogaard and Detzel (2012) who show that policy uncertainty reduces asset returns, Handley and Limao (2012) who show that trade-policy uncertainty delays firm entry decisions, and Gulen and Ion (2012) who find our policy-uncertainty index reduces firm investment.

Our paper proceeds as follows. Section 2 describes the data we use to construct our policy-related uncertainty indices in more detail. Section 3 identifies specific policy areas that underlie policy uncertainty levels and movements over time. Section 4 reports estimates for the dynamic responses of aggregate economic outcomes to policy-related uncertainty shocks. Section 5 considers several proof-of-concept tests for our policyrelated uncertainty indexes and comparisons to other uncertainty measures. Section 6 concludes and lays out some directions for future research.

\footnotetext{
${ }^{3}$ Dixit and Pindyck (1994) offer a good and detailed review of the early theoretical literature. Recent empirical papers include Bloom (2009), Alexopolous and Cohen (2011), Bloom, Floetotto, Jaimovich, Saporta and Terry (2012) and Bachman et al. (2013).
} 


\section{MEASURING ECONOMIC POLICY UNCERTAINTY}

To measure policy-related economic uncertainty, we construct an index from three types of underlying components. One component quantifies newspaper coverage of policy-related economic uncertainty. A second component reflects the number and size of federal tax code provisions set to expire in future years. The third component uses disagreement among economic forecasters about policy relevant variables as a proxy for uncertainty.

\subsection{News coverage about policy-related economic uncertainty}

Our first component is an index of search results from 10 large newspapers. The newspapers included in our index are USA Today, the Miami Herald, the Chicago Tribune, the Washington Post, the Los Angeles Times, the Boston Globe, the San Francisco Chronicle, the Dallas Morning News, the New York Times, and the Wall Street Journal. To construct the index, we perform month-by-month searches of each paper, starting in January of 1985, for terms related to economic and policy uncertainty. In particular, we search for articles containing the term 'uncertainty' or 'uncertain', the terms 'economic' or 'economy' and one or more of the following terms: 'congress', 'deficit', 'federal reserve', 'legislation', 'regulation' or 'white house'. In other words, to meet our criteria for inclusion the article must include terms in all three categories pertaining to uncertainty, the economy and policy. Our goal is to select articles in US news sources that discuss something about uncertainty over economic. We count the number of articles that satisfy our search criteria each month, giving us a monthly series for each paper.

One difficulty with a straight news search index is changing volumes of news articles produced by each paper, as well as differing amounts that are catalogued online. So, to construct our index, we normalize the raw counts of EPU-related articles by the total number of monthly news articles in the same newspapers. We then normalize each newspapers index to have a standard-deviation of 1 over 1985-2009 and add up the indices for all 10 papers. Finally, we rescale the overall series so it averages to an average value of 100 from 1985-2009. 
Figure 2 shows our 10-Paper News index of policy-related economic uncertainty. There are clear spikes corresponding to Black Monday, the first and second Gulf Wars, the 1992 presidential election, 9/11, the 2009 stimulus debate, the Lehman Brothers bankruptcy and TARP bailout, intensification of the European debt crisis, the 2010 midterm elections, and the recent debt-ceiling dispute, among other events. ${ }^{4}$

\subsection{Tax Code Expiration Data}

The second component of our index draws on data from the Congressional Budget Office (CBO): lists of temporary federal tax code provisions set to expire in coming years. Temporary tax measures are a source of uncertainty for both businesses and households because Congress often decides to extend or not extend them at the last minute, undermining stability of and certainty about the tax code. One recent example involves the Bush-era income tax cuts originally set to expire at the end of 2010. Democrats and Republicans staked out opposing positions about whether to reverse these tax cuts and, if so, for which taxpayers. Rather than resolving the uncertainty in advance, Congress waited until December 2010 before acting, much as they did more recently with the Fiscal Cliff crisis in December 2012.

Temporary tax code provisions also lead to murkier outlooks for federal spending and borrowing and to discrepancies between the tax revenue projections of the CBO and the Office of Management and Budget (OMB). The CBO uses 'current law' as a baseline taking into account all scheduled tax expirations, while the OMB uses 'current policy' as a baseline under its assessment of which temporary provisions are likely to be extended. The CBO also produces alternative projections based on its judgments about 'current policy'.

The CBO reports contain data on scheduled expirations of federal tax code provisions in the contemporaneous calendar year and each of the following 10 years. The CBO document briefly describes the tax code provision, its value, and identifies the

\footnotetext{
${ }^{4}$ Some notable political events do not generate high levels of economic policy uncertainty according to our news-based index. For instance, we find no large spike around the time of the federal government shutdowns from November 1995 to January 1996. While we found more than 8,000 articles mentioning these government shutdowns, less than $25 \%$ also mention the economy, less than $2 \%$ mention uncertainty, and only $1 \%$ mentions both. We take this finding to mean that, while some events are politically tumultuous, they do not necessarily raise economic policy uncertainty.
} 
scheduled expiration month, typically but not always December. We apply a simple weighting to these data in January of each year. First we sum the total dollar amount of the expiring tax provisions for each year in a 10-year horizon (using the absolute value of dollars, as some expiring provisions are taxes, and some are tax cuts). Then we discount these future expirations by $50 \%$ per year, and sum the discounted number of dollarweighted tax code expirations to obtain an index value for each January, which we then hold constant during the calendar year. We utilize a high discount rate because many expiring tax code provisions are regularly renewed, and are unlikely to be a major source of uncertainty until the expiration date looms near.

Figure 3 plots the discounted sum of expiring tax provisions. Here we see a generally increasing series. This pattern reflects a secular increase in the number of tax provisions involving temporary measures subject to continual renewal, debate and uncertainty. The one earlier bump in 2002-2004 was the accelerated capital depreciation allowances introduced in 2002.

\subsection{Economic Forecaster Disagreement}

The third component of our policy-related uncertainty index draws on the Federal Reserve Bank of Philadelphia's Survey of Professional Forecasters (SPF). This quarterly survey covers a wide range of macroeconomic variables. Each quarter, every forecaster receives a form in which to fill out values corresponding to forecasts for a variety of variables in each of the next five quarters, as well as annualized values for the following 2 years. ${ }^{5}$ We utilize the individual-level data for three of the forecast variables, the consumer price index (CPI), purchase of goods and services by state and local governments, and purchases of goods and services by the federal government. For each series, we look at the quarterly forecasts for one year in the future. We chose these variables because they are directly influenced by monetary policy and fiscal policy decisions. We treat the dispersion in the forecasts of these variables as proxies for uncertainty about future monetary policy and about government purchases of goods and

\footnotetext{
${ }^{5}$ A sample form for Q1 2010 can be seen at http://www.philadelphiafed.org/research-and-data/real-timecenter/survey-of-professional-forecasters/form-examples/SpfForm-10Q1.pdf
} 
services at the federal, state, and local level. This approach builds on a long literature using disagreement among forecasters as a proxy for economic uncertainty. ${ }^{6}$

For inflation, we look at the individual forecasts for the quarterly inflation rates four quarters in the future as measured by the CPI. To construct the dispersion component, we then take the interquartile range of each set of inflation rate forecasts in each quarter. We use the raw interquartile range because we believe that the absolute level of the CPI is the important factor, not only the uncertainty relative to a mean CPI level.

For both federal and state and local government purchases, we divide the interquartile range of four-quarter-ahead forecasts by the median four-quarter-ahead forecast and multiply that quantity by a 5-year backward-looking moving average for the ratio of nominal purchases, either federal or state/local, to nominal GDP. We hold the values of the forecaster disagreement measures constant within each calendar quarter. Finally, we sum the two indices, weighted by their nominal sizes, to construct a single federal/state/local index.

Figure 4 shows the dispersion in forecasts for federal, state, and local purchases four quarters in the future. Noteworthy jumps occur around the passage of Balanced Budget legislation in 1985 and 1987, the 1992 presidential election, 9/11 and the $2^{\text {nd }}$ Gulf War, and the stimulus spending debates from 2008 to 2010. Figure 5 shows the dispersion in CPI forecasts, with larger spikes coming in both earlier and in later years following federal budgetary indecision, major actions by the Federal Reserve, and recent stimulus measures by the federal government.

\subsection{Constructing our overall Economic Policy Uncertainty index}

To construct our overall index of policy-related economy uncertainty, we first normalize each component by its own standard deviation prior to January 2012. We then compute the average value of the components, using weights of $1 / 2$ on our broad news-

\footnotetext{
${ }^{6}$ See, for example, Zarnowitz and Lambros (1987), Bomberger (1996), Giordani and Soderlind (2004) and Boero, Smith and Wallis (2008). These papers find a significant correlation between disagreement among forecasters over future outcomes such as inflation and other measures of uncertainty. However, there is disagreement over the strength and the interpretation of the link between forecaster disagreement and uncertainty about future outcomes. See, for example, Rich and Tracy (2010), who claim a very weak link for inflation.
} 
based policy uncertainty index and $1 / 6$ on each of our other three measures (the tax expirations index, the CPI forecast disagreement measure, and the federal/state/local purchases disagreement measure). These weights roughly reflect the distribution of specific sources of policy-related uncertainty, as measured in Table 1 below, giving more weight to indices with a broader coverage. To deal with missing values, we set the pre1991 tax expiration index equal to its 1991 value. Finally, we normalize our overall index to have a value of 100 from 1985 to 2009 , the first 25 years of the period covered by our data.

In addition to our preferred weighting, we also calculate Economic Policy Uncertainty indices using two other weighting methodologies. First, we equally weight the news-based measure, the combination of the forecast disagreement measures, and the tax expiration measure. The result series, shown in Figure A1, is very similar to our preferred measure. Second, we perform a principle component factor analysis on our four series to obtain weights for each component. This approach yields weights of 0.22 on our news-based index, 0.27 on our tax expirations index, 0.29 on the CPI forecast disagreement measure, and 0.21 on our federal, state, and local purchases disagreement measure. We again find a similar final index, plotted in Figure A5. Our preferred index has correlations of 0.962 and 0.945 with the equally weighted and principle components weighted indices, respectively. All three versions of the overall index yield very similar results in the VAR-based discussed in Section 4 below.

Figure 1 displays our preferred version of our Economic Policy Uncertainty Index. We find spikes in uncertainty corresponding to several well-known prominent events and a substantially higher level of uncertainty since the onset of the Great Recession in 2007. In particular, we find spikes associated with consequential presidential elections, wars, 9/11, contentious budget battles, and a number of spikes during and after the Great Recession. The average index value is 71 in 2006 (the last year before the current crisis) and 172 in the first eight months of 2011, a difference of 101. We use this increase in the average index value when quantifying the responses of output, investment and employment to policy uncertainty shocks.

We update our Economic Policy Uncertainty Index on a monthly basis as more data becomes available, and post the data at www.policyuncertainty.com. 


\subsection{Measuring Policy Uncertainty in Europe}

We also construct economic policy uncertainty indices in a number of other countries. In these other countries since we do not typically have large amounts of expiring tax code provisions, we base our overall policy uncertainty indices on $50 \%$ newspaper searches and 50\% forecaster disagreement. In particular, for our European index (shown in Figure 6) we use 2 papers from each of the largest 5 European economies (Germany, the United Kingdom, France, Italy, and Spain). The papers include El Pais, El Mundo, Corriere della Sera, La Repubblica, Le Monde, Le Figaro, the Financial Times, The Times of London, Handelsblatt, and FAZ.

As with our American newspaper index, we utilize the number of news articles containing the terms uncertain or uncertainty, economic or economy, as well as policy relevant terms (here scaled by the smoothed number of articles containing 'today'). Policy relevant terms include: 'policy', 'tax', 'spending', 'regulation', 'central bank', 'budget', and 'deficit'. All news searches are done in the native language of the paper in question. Each paper-specific series is normalized to standard deviation 1 prior to 2011 and then summed. The series is normalized to mean 100 prior to 2011 .

To measure forecaster disagreement we use the Consensus Economics forecast database of public expenditure for each European country (because the SPF only provides US forecasts). ${ }^{8}$ For each country, we use data on individual forecasts for the following calendar year of CPI and federal budget balances, taking the interquartile range of each set of country-month forecasts. Due to the nature of the forecasts, asking about the following calendar year and not 1 year ahead, the forecasts become mechanically more accurate as months progress in a year. To correct for this, we deseasonalize the series of interquartile ranges. For the CPI disagreement measure, we then use the raw values. For the budget balance, we scale by a country's GDP. Each country's index is then scaled to standard deviation 1 and summed to create a single European-wide index.

\footnotetext{
${ }^{7}$ These terms differ slightly from our US terms because they were the version we used in our initial US index before undertaking a detailed audit (see section 3.1 and Baker, Bloom and Davis, 2012). When we updated our US index on the basis of this audit we decided not to update our European index until we have performed a similarly detailed audit on our European terms, which we have yet to complete.

${ }^{8}$ From Consensus Economics (http://www.consensuseconomics.com/)
} 


\section{EVALUATING OUR POLICY UNCERTAINTY MEASURE}

Before examining our index any further we first evaluate to what extent it provides an accurate and unbiased measure of policy uncertainty. In summary, we provide data that suggests we have a measure of economic policy uncertainty, that while noisy, does match up to what a human reader would call policy uncertainty, is consistent over time with other measures of policy uncertainty like the frequency of the word "uncertain" in the FOMC Beige Book and the number of stock-market jumps driven by policy news, and does not appear to be heavily impacted by newspaper political slant.

\subsection{The Human News Audit}

One approach evaluating our data was to undertake a human audit of 3,500 articles from our 10 newspaper to compare the results from a human reading of the articles to our computerized algorithm.

To perform this we started by generating the universe of all articles from the Los Angeles Times, New York Times, Dallas Morning News, San Francisco Chronicle, and Miami Herald that contained the words "uncertain" or "uncertainty" and "economic" or "economy", as this is the population of papers that could potentially be about policy uncertainty ${ }^{9}$. These particular papers were chosen because they provided full on-line access to the articles (rather than just search result counts). ${ }^{10}$ From this set we then randomly selected 10 articles each month from January 1985 until June 2012.

These 3,500 articles were then individually read by a team of 5 undergraduates to evaluate them on a range of criteria, most importantly if they were about "economic policy uncertainty" (EPU=1). To define this we generated a 49 page PowerPoint audit guide (see www.policyuncertainty.com/Audit_Guide.pptx), which provided a set of

\footnotetext{
${ }^{9}$ We could of coursed used the whole universe of articles, but since few articles in newspapers are potentially about policy uncertainty - most are about non-policy news, business news, entertainment, sports, weather etc - it seemed to efficient to somewhat narrow down the audit population in advance.

${ }_{10}$ These newspapers allowed us to open and read the full text of any article since 1985. The other newspapers provided search results, including the number of articles and the headlines arising from each search query, but not the ability to read the full article. For our policy uncertainty index we only need article counts in response to our search query for each month.
} 
detailed rules for defining policy uncertainty, pre-coded example articles, frequently asked questions, and how to deal with difficult to define articles. ${ }^{11}$

Our key definition was that an article was about policy uncertainty if it remarked about any policy-related aspects of economic uncertainty, even briefly, including:

1. Uncertainty over who will make future economic policy decisions (e.g. presidential and congressional elections or political appointments)

2. Uncertainty over what and when economic policies will be undertaken (e.g. when and by how much taxes will increases)

3. Uncertainty over the economic effects of past, present and future policy actions (e.g. the eventual impact of TARP or QE3)

Auditors were given articles in a random order to ensure that no learning effects occur over the sample, and each auditor had an overlap of $1 / 5$ of their articles with other auditors so we could cross-check the audit consistency. In summary, we found that the average correlation between the EPU measures of any two of our audit team members was 0.76 , confirming the audit process was consistent and reliable.

With this audit we did two pieces of analysis. First, we ran a search across all $\sim 28,000$ permutations of 4 or more combinations of the likely policy words we had identified from our newspaper human reads. This list included terms such as "regulation, budget, spending, policy, deficit, tax, federal reserve, government, congress, senate, president, legislation, government spending, government policy, veto, and federal spending", and was selected words that frequently appeared in articles which we read as discussing policy uncertainty. We then evaluated this set of 28,000 permutations primarily along two dimensions: (A) ratio of false positives (how many articles that our human audit coded as $E P U=0$ the computer search coded as $E P U=1)$ and $(B)$ ratio of false negatives (how many articles that our human audit coded as EPU=1 our computer search coded as EPU $=0$ ). We selected the set of words with the lowest combined ratio of false positives and false negatives, as shown in Figure 7. This was the set 'congress', 'deficit', 'federal reserve', 'legislation', 'regulation' or 'white house'.

\footnotetext{
${ }^{11}$ This auditing guide and process itself was developed by two prior rounds in which we (the authors) audited first 200 articles, and then had two undergrads audit around 1800 articles.
} 
The second piece of analysis was to compare our human audited data and the actual data individually and as a data series over time. The match-up was extremely good: the index of economic policy uncertainty from our human audit had a correlation of 0.59 with our computerized series at the monthly level and 0.7 at quarterly level (with 3,500 articles we have samples of only 10.6 articles per month), suggesting out computerized audit does a good job of tracking over trends.

\subsection{Beige Book Analysis}

A second method of evaluating our economic policy uncertainty index is to examine this alongside the frequency that the word "uncertainty" in the Federal Open Market Committee's (FOMC's) Beige Book. The Beige Book has been issued about every six weeks, two weeks before each regularly scheduled FOMC meeting, since October 1983. It is a 15,000 word summary of the options of contacts with the regional Federal Reserve Boards around the country, based on their business contacts and local perspectives. We count the frequency of the word "uncertain" (which includes all stems like "uncertainty") appearing in the Beige Book. We also had an undergraduate read through the beige book and categorize every appearance of the word uncertainty into a "policy" or "non-policy" context, and if it was a policy context what policy is referred to.

In Figure 8 we have plotted the frequency of uncertainty mentions and "policy context" uncertainty mentions in the Beige Book since 1983Q4. It is very clear the frequency of uncertainty arising in the Beige Book shows a very similar pattern to our overall EPU index (correlation=0.802), with high levels post 2008 and smaller spikes after Gulf War I, II and 9/11. This suggests that when our policy uncertainty index registers high policy uncertainty the FOMC Beige Book discusses this frequently, suggesting it is a real concern of participants in their informal survey of business contacts. Interestingly, the policy subcomponent has increased even more sharply since 2008, suggesting a large share of the overall increase in uncertainty that the Beige Book is picking up is policy related. 


\subsection{Stock-market jump analysis}

A third method of evaluating our EPU index is to compare this to the factors underlying large jumps in the stock-market. The idea is that if policy uncertainty is higher, we would expect policy news to play a more important role in driving the stock market. For example, this would arise from a model in which the stock-market index (X) follows a geometric Brownian motion with stochastic volatility:

$$
\mathrm{dX}_{\mathrm{t}}=\mu \mathrm{dt}+\sigma_{\mathrm{t}-1}^{\mathrm{E}} \mathrm{dw}_{\mathrm{t}}^{\mathrm{E}}+\sigma_{\mathrm{t}-1}^{\mathrm{P}} \mathrm{dw}_{\mathrm{t}}^{\mathrm{P}} \quad \text { where } \mathrm{dw}_{\mathrm{t}}^{\mathrm{i}} \sim \mathrm{N}(0,1), \mathrm{i}=\mathrm{E} \text { or } \mathrm{P}
$$

where $\mu$ is the long-run trend, $\sigma_{\mathrm{t}-1}^{\mathrm{E}}$ is economic uncertainty, $\mathrm{dw}_{\mathrm{t}}^{\mathrm{E}}$ are economic shocks, $\sigma^{\mathrm{P}}{ }_{\mathrm{t}-1}$ is policy uncertainty and $\mathrm{dw}_{\mathrm{t}}^{\mathrm{P}}$ are the policy shocks. Then, when policy uncertainty $\left(\sigma_{t-1}^{\mathrm{P}}\right)$ is higher we should also expect to see more jumps in the stock-market $(\mathrm{X})$ driven by policy shocks.

To evaluate this claim, we examined the New York Times on the day after any movement of the S\&P 500 index of greater than 2.5\% up or down. Overall, since 1980, there have been about 290 such large movements, with 120 of them in just the last 4 years alone. From the New York Times, we find the article explaining the previous day's large stock market movements - which almost always exists because jumps of $2.5 \%$ or more are rare events (for example there were none from 2004 to 2006) - and examine the reason provided for the jump.

We then allocate each reason to broad categories such as macroeconomic news (e.g. unemployment figures or GDP growth data), earnings or profit reports, or policyrelated reasons such as government announcements about new regulations, taxes, or fiscal policy.

This is shown in Table 1, displaying a clear increase is the number and share of stock-market jumps associated with policy since 2008. Not surprisingly, this stockmarket measure of policy uncertainty is also strongly correlated with our EPU index (0.67 on an annual basis). This suggests that many of the same policies that drive our EPU index upwards are also driving an increasing share of large movements in the stock market.

One concern is the reliability of our methodology of using the following days New York Times to identify the causes of stock-market jumps. In Baker, Bloom and Davis (2013) we investigate this in detail - showing the results are very similar using a 
number of other newspapers, like the Wall Street Journal, LA Times, Boston Globe and the Washington Post. We also extend this data back across time and across countries, and again find a very close correspondence between our policy uncertainty measures in different countries and the number of stock-market jumps attributed to policy.

\subsection{Evaluating Political Slant}

Another concern over economic policy uncertainty index is the potential for political slant in the new media. For example, it could be that the press is right or left wing leaning, and so tends to over or under emphasize policy uncertainty depending on the part of the President and/or Congress.

To evaluate this we split our 10 newspapers index into the most Republic and most Democrat 5 papers using the Gentzkow and Shapiro (2010) media slant index. This index accords newspapers a party slant based on the frequency with which they use words that are used heavily by one party in Congress. For example, a newspaper that uses the phrases "death tax", "personal account" and "war on terror" (which are frequently used by Republican) would have a right slant index, while papers frequently using "estate tax", "private account" and "war in Iraq" (the Democrat versions) would have a left slant index.

Our ten newspapers split into their most right and left halves are shown in Figure 9. From this it is clear both groups of papers tend to move together over time, suggesting that most variations in reporting of policy uncertainty are apolitical. In Appendix Table A1 we also more detailed statistical analysis of political slant. We find that, when a 'same-party' president is in power, a one standard deviation change in media bias results in only a statistically insignificant $\sim 3 \%$ change in our news-based economic policy uncertainty measure. Correcting for this small shift yields an extremely similar newsbased measure of EPU. Overall, we conclude that while we can occasionally find some statistically significant evidence for media slant in reporting about economic policy uncertainty reporting, it is not robust and is always quantitatively very small. 


\section{THE SOURCES AND HORIZON OF POLICY UNCERTAINTY}

In this section we investigate what particular types of policy are driving our overall policy uncertainty index, to what extent policy uncertainty is linked to other types of uncertainty, and what is the time-horizon it reflects.

\subsection{Type of Policy Uncertainty}

One obvious question that arises from our index is what types of policies are causing these changes overall economy policy uncertainty. To investigate this we create sub-indices for specific policy areas, like taxes, monetary policy and regulation. To do this we require an article to satisfy all the search criteria for our main policy uncertainty index plus mention category-specific terms such as "Federal Reserve Board", "The Fed, "interest rate" or "inflation" for our Monetary Policy category, or "taxes" for our Taxes category.

This is undertaken using the Access World News Newsbank ("Newsbank"), which is a news source covering about 2,000 US national and regional newspapers. We use Newsbank for these sub-indices due to its larger sample size of 2,000 (rather than 10) newspapers which means we can drill down in more detail on individual policy areas. So we can drill down into the finer causes of policy uncertainty while maintaining a sufficient volume of articles for an analysis. However, the downside of Newsbank is that the composition of papers changes over time, so for our primary index we use our 10paper news-based measure. The correlation between for the basic monthly policy uncertainty index generated from our 10 newspapers and from Newsbank is 0.94, suggesting the two sources given similar results if used to create the overall index.

Table 2 reports the results for nine categories of policy uncertainty. The second row reports average values of our Newsbank Index of Economic Policy Uncertainty in each indicated period (scaling by the total number of articles in a period), expressed as a percentage of the average index value for the entire sample period from 1985:1 to 2012:10. For example, the value of 109.0 for Economic Policy Uncertainty from 1985:1 to $1990: 6$ says that the value of the index in that period is $109.0 \%$ of its average value over the full sample period. 
The top row of Table 2 reports the value of our Newsbank Index of Overall Economic Uncertainty, also expressed as a percentage of the average value of our Newsbank Index of Economic Policy Uncertainty. Entries in the lower rows report the values for specific policy categories. For example, the value of 76.7 for "Fiscal Policy" from 2010:1 to 2012:10 says that the number of scaled references to fiscal policy (tax or spending) uncertainty in this period is $76.7 \%$ of the average number of scaled references to all forms of policy-related uncertainty during the full $1985: 1$ to $2012: 10$ period. That is more than three quarters of all articles on economic policy uncertainty over this period also mentioned words connected with fiscal policy like "Tax", "Government Spending" or "Budget Deficit" (see notes to Table 2 for details).

The key finding from Table 2 is that fiscal policy - both tax and spending - and health care and entitlement policies have been the big drivers of the recent overall increase in policy uncertainty. Strikingly, monetary policy uncertainty does not appear to have increased, presumably because the typical paper in the Newsbank index of about 2000 papers - which is a regional newspaper - does not consider monetary policy uncertainty to have increased given relatively low and stable inflation and interest rates.

Looking further as Table 2 we also see that both "financial regulation" policy uncertainty rises three-fold post 2008, and "foreign sovereign debt and currency crisis" policy uncertainty rises ten-fold post 2010. However, both categories how low absolute levels so these increases do not have much impact on the overall index. This suggests that the typical US regional newspaper in the Newsbank sample is not focusing much on financial regulation and the European debt crisis, but is more concerned with policy uncertainty around taxes, government spending, healthcare and entitlement reform. Looking at earlier periods we also "national security and war" policy uncertainty looms large around Gulf War I and after 9/11.

In Table 3 we also provide a breakdown of policy uncertainty areas using our FOMC Beige Book data, which reveals broadly similar patterns to our news analysis in Table 2. The increase in policy uncertainty post 2010 is heavily driven by "fiscal policy" 12 , which alone accounts for more than $50 \%$ of the overall increase. There is also

\footnotetext{
${ }^{12}$ The mentions of uncertainty in the Beige Book that have enough discussion around can be broken down into tax and government spending sub-components of fiscal policy, with both elements showing an increase
} 
an increase in "health care", "financial regulation" and "foreign sovereign debt and currency crisis" policy uncertainty. The category "U.S. Elections \& Leadership Changes" uncertainty also rises reflecting the presidential election in 2012, as do two residual categories (other specified and unspecified policies). Maybe not surprisingly, given this is a FOMC produced document there is no discussion of monetary policy uncertainty.

\subsection{Policy Uncertainty and the VIX}

Another commonly used high-frequency measure of uncertainty is the VIX index of 30-day implied volatility on the S\&P500 index, provided by the Chicago Board of Options and Exchange (CBOE). This is an index constructed from a weighted average of European-style call and put options on the S\&P500 that straddle the 30-day maturity and cover a wide range of strikes (see CBOE (2004) for details).

Figure 10 shows the VIX plotted alongside our policy uncertainty index, and it is clear these are linked (correlation $=0.578$ ) but also have substantial independent variation. In particular, the VIX appeared to rise far more after the Asian crisis of 1997, the LTCM and Russian Debt crisis of 1998, after the stock-market scandals of early 2002 (WorldCom, Enron etc) and right after Lehman's collapsed in 2008. These are all clearly events that have a strong financial and stock-market connection. In contrast the policyuncertainty index spiked relatively more after Gulf Wars, the Clinton and Obama Election, and from 2009 onwards especially during the debt-ceiling dispute during the summer of 2011. These are more policy relevant events, in that while they have financial implications (for example, the impact of the Gulf Wars on oil prices) they also have much broader policy implications.

These differences could also reflect differences in measurement, since the VIX is based on traded put and call options while the EPU index is based 50\% on newspaper coverage. To investigate whether this matters we created an "equity market uncertainty" news index, which calculates an index of the proportion of articles in our 10 newspapers that contain the words "uncertain/uncertainty" and "economic/economy" and "stock price" or "equity price" or "stock market". This created in exactly the same way as our

in 2010. However, several times when the Beige Book mentions the word uncertainty there is too little discussion to attribute this to tax or spending. 
newspaper policy uncertainty index, except that we search for these three stock-market terms rather than the six policy terms. Figure 11 plots this equity market uncertainty index is clearly much more correlated with the VIX than our general policy uncertainty index was (correlations of 0.733 and 0.578 respectively). Our equity market uncertainty index appears to jump and fall in line with the VIX, and in particular is not as highly elevated since 2009 in contrast with our EPU index. Hence, we believe that the difference between the VIX and the EPU index is not simply due to one being market based and the other being partially news based.

Another difference is of course that the VIX is focused on a 30-day measure of volatility while our policy uncertainty index has no explicit timeframe, something we turn to next. To evaluate we compare our policy uncertainty index against 30-day implied volatility from the VIX index and against 10 -year implied volatility calculated using the same formula as for the VIX (see CBOE 2004) but for a basket of 10 year put and call options $^{13}$. We find the EPU index has a much higher correlation (correlation=0.855) with the 10-year financial uncertainty index than with the 1-month financial uncertainty index (correlation=0.578). In particular, since late 2008 the 1-month implied volatility index has fallen, while both our EPU index and the 10-year implied volatility indices remain high (see also figure A2 in the Appendix).

In fact looking across a range of different maturities of financial volatility indices we find these are increasingly correlated with our EPU index as the time horizon moves out. In particular the correlations of the 1-month, 3-month, 6-month, 1-year, 2-year, 3year, 5-year and 10-year implied volatility indices with the EPU index are 0.578, 0.644, $0.715,0.777,0.820,0.840,0.857$ and 0.855 respectively. Hence, at least over the timeperiod of 2002-2012 spanned by this data our policy uncertainty index seems to be more long-run than short-run focused.

\section{THE POTENTIAL IMPACT OF POLICY UNCERTAINTY}

As we discussed in the introduction, an open question is to what extent - if any has heightened policy uncertainty acted to impede the recovery from the recession of

\footnotetext{
${ }^{13}$ We thank Krag Gregory and Jose Rangel from Goldman Sachs for providing this data for this, which was came from (Gregory and Rangel, 2012).
} 
2007-2009, and more generally drive the business cycle. To investigate this, we estimate simple Vector Auto Regressions (VARs) estimates to try and characterize the dynamic relationship between policy uncertainty and economic outcomes like GDP, private investment and employment.

\subsection{Vector Auto Regression estimates of economic activity and policy uncertainty}

We start by estimating a VAR and recovering orthogonal shocks using a Cholesky decomposition of the following variables: our policy uncertainty index, the $\log$ of the S\&P 500 index to control for broader economic conditions, the federal funds rate to control for interest rates, log employment, and log real industrial production. In our baseline specification, we run the VAR on monthly data with six monthly lags, and a monthly time trend.

This approach identifies dynamic relationships among the variables using our Cholesky ordering and differences in the timing of movements in the variables. So, for example, it could be that policy uncertainty causes recessions, or that policy uncertainty is a forward-looking variable that rises in advance of anticipated recessions. With these caveats in mind, our VAR-based results provide evidence at least of important comovements between our index of policy-related uncertainty and economic activity, with some suggestive evidence on causation.

Looking at Figure 12, we see that a 112 point innovation in policy uncertainty (the rise in our policy uncertainty index from 2006 to 2011) is followed by a persistent fall in real industrial production with a peak negative impact of about $-2.5 \%$ at 14 months. Similarly, there is a persistent fall in aggregate employment following a policy uncertainty shocks, with a peak response of 2.3 million jobs after 20 months. These dynamic responses are substantial, lending support to recent concerns about the potentially damaging economic consequences of policy uncertainty.

The estimated effects of political uncertainty on output and employment are robust to several modifications to the VAR specification, Cholesky ordering, and policy uncertainty index construction. Figure 13 shows the results of a sensitivity analysis for the industrial production response to policy uncertainty shocks. We consider three months and nine months of lags rather than six months, reverse the Cholesky ordering 
used to construct orthogonal shocks, use a version of the policy uncertainty index that weights all components equally, consider a bivariate VAR with policy uncertainty and industrial production only, and add the VIX index as the first measure in the VAR to control for overall economic uncertainty. Robustness results for employment look similar, with estimated falls of around 2 to 3 million jobs following a policy uncertainty shock across all the specifications estimated in Figure 13.

Figure 14 considers a VAR-based estimated effect of policy uncertainty shocks on real GDP and investment using quarterly data from the national income accounts. Using the same size shock as before, we find a peak estimated effect on GDP of $2.3 \%$ after four quarters. We find a much larger effect on private investment, with a peak decline of $14 \%$ after three quarters. Although based on a different empirical approach, our investment results are very much in line with the estimated effects of election uncertainty in Julio and Yook (2010) and Durnev (2010). Consumption (not shown in the figures) also drops in a similar fashion to GDP, with durable consumption showing a slightly larger drop and recovery than non-durable consumption.

\subsection{Policy uncertainty or economic confidence?}

Another question is to what extent our estimated impact of uncertainty reflects the response of economic activity to an increase in uncertainty (a mean preserving increase in the variance of policy) versus the response to increased uncertainty alongside bad news. This is important as periods of increased economic policy uncertainty also tend to be periods of bad economic news. So our changes in "uncertainty" could be reflecting changes in "confidence", a term which often implies both mean and variance effects.

To control for this we first include the level of the S\&P500 stock-market index in all our VAR estimations. Given stock-markets are forward looking this should hopefully reflect future expectations of business conditions. But as a second robustness test we also try including the index of consumer confidence from the Michigan Consumer Sentiment Index. ${ }^{14}$ In Figure 15 we show the VAR estimates after including this consumer

\footnotetext{
14 This index is constructed through phone surveys of consumers and seeks to determine how consumers view the short-term economy, the long-term economy, and their own financial situation. It takes the difference between the percent answering positively and that answering negatively for each of 5 questions, then averages these differences and normalizes by the base period (December 1968) total. This has a
} 
confidence index as the second measure after uncertainty (in the top panel) and as the first measure before uncertainty (in the bottom panel). In both cases the estimated impact is lower, suggesting that consumer confidence does proxy for part of the predictive power of our economic policy uncertainty measure. But, nevertheless we still get a drop and recovery in production after an economic policy uncertainty shock, suggesting this has significant additional predictive power over and above consumer confidence.

\section{CONCLUSION}

Economic policy uncertainty (EPU) has become the subject of contentious debate since the recession of 2007-2009. Commentators have made two broad claims: first, that policy uncertainty has increased since the onset of the recession, and second that this increase in policy uncertainty has impeded the recovery. This paper seeks to investigate both claims, finding strong support for the first claim, in that our economic policy uncertainty index has increased by more than $50 \%$ since 2007 . On the second claim we find that positive innovations in our EPU index in simple VAR models foreshadow sizable declines in GDP and employment, although this evidence is associative rather than necessarily causal.

Our EPU index is built on three components: the frequency of news media references to economic policy uncertainty, the number of federal tax code provisions set to expire, and the extent of forecaster disagreement over future inflation and government purchases. This EPU index spikes near consequential presidential elections and major events such as the Gulf wars and the 9/11 attack. It also rises steeply from 2008 onward.

We also evaluate our EPU index, first on a sample of 3,500 human audited news articles, and second against other measures of policy uncertainty like the frequency of the word "uncertainty" in the FOMC Beige Book and the number of policy related jumps in the stock-market, finding evidence suggesting our EPU index is a good proxy of real economic policy uncertainty.

correlation with our uncertainty index of -0.742 . We chose the Michigan index as the more commonly used consumer confidence index, but other indices give similar results as they are highly correlated with the Michigan Index - for example, the Bloomberg Confidence index has a correlation of 0.943 with the Michigan index and the Conference Board Confidence index has a correlation of 0.912 with the Michigan index. 
Drilling down into our index we find that the post-2008 increases are driven mainly by tax, spending and healthcare policy uncertainty. Perhaps surprisingly we find no evidence of an increase in monetary policy uncertainty after 2008. One interpretation is that since inflation and interest rates have both been low and stable since mid-2008 onwards, monetary policy is not seen by the news media as contributing to economic policy uncertainty.

Finally, VAR estimates show that an innovation in policy uncertainty equal to the actual increase from 2006 to 2011 foreshadows declines in GDP peaking at $2.3 \%$ and in employment peaking at 2.3 million. These effects peak at about 18 months out, and appear to be robust to a variety of different measures, choices of VAR variables and ordering and even detrending. But while the VAR results are empirically robust, it is less clear whether rises in policy uncertainty cause the subsequent drops in economic activity, or simply forecast them because policy making is a forward looking process.

In terms of future work we want to extend our measurement of policy uncertainty, first by pushing the data across more countries and back in time. We also want to refine the methodology, for example using information on the location of terms about economic policy uncertainty within news articles, such as whether all our key search terms are in the same sentence or paragraph. As importantly we want to try and extend our research to improve our identification of the causal impact of policy uncertainty on the economy. Right now it is hard to empirically distinguish cause and effect because of the forward looking nature of policy making, requiring us to exploit exogenous policy-shocks to try to deal with this. 


\section{REFERENCES:}

Alexopoulos, M. and J. Cohen, 2009. "Nothing to Fear but Fear itself? Exploring the effect of economic uncertainty", Manuscript, University of Toronto working paper.

Bachmann, Rüdiger, Steffen Elstener, and Eric Sims (2013). "Uncertainty and Economic Activity: Evidence from Business Survey Data,", forthcoming AEJ Macro.

Baker, Scott, Bloom, Nicholas and Davis, Steve, (2013), "What explains stock market jumps", Stanford mimeo.

Baker, Scott, Bloom, Nicholas and Davis, Steve, (2012), "Measuring economic policy uncertainty", Stanford mimeo.

Bernanke, B. (1983): "Irreversibility, Uncertainty and Cyclical Investment," Quarterly Journal of Economics, 98, pp. 85-106.

Bloom, Nick. (2009): “The Impact of Uncertainty Shocks," Econometrica, 77, pp. 623685.

Boero, Gianna, Jeremy Smith, and Kenneth F. Wallis, "Uncertainty and Disagreement in Economic Prediction” Economic Journal 118 (2008), 1107-1127.

Bomberger, W. A. (1996), "Disagreement as a Measure of Uncertainty", Journal of Money, Credit and Banking, 28(3), 381-392.

Born, Benjamin and Johannes Pfeifer, 2011. "Policy Risk and the Business Cycle," University of Bonn.

Brogaard, J and Detzel, A. (2012), “The Asset Pricing Implications of Government Economic Policy Uncertainty", University of Washington mimeo

Chicago Board Options Exchange (2004). "VIX CBOE Volatility Index," White Paper.

Dixit, A. and R. Pindyck (1994): Investment Under Uncertainty. Princeton, NJ: Princeton University Press.

Durnev, Art, 2010. "The Real Effects of Political Uncertainty: Elections and Investment Sensitivity to Stock Prices," working paper, McGill University, September.

Fernandez-Villaverde, Jesus, Guerron-Quintana, Pablo, Kuester, Keith and Juan RubioRamirez (2011), "Fiscal volatility shocks and economic activity", Penn mimeo.

Friedman, Milton, 1968, "The Role of Monetary Policy" The American Economic Review, 58.

Gentzkow, M and Shapiro, J (2010), "What drives media slant? Evidence from US Daily newspapers", Econometrica 78(1), pp. 35-71.

Gilchrist, Simon, Jae W. Sim and Egon Zakrajsek, 2010, "Uncertainty, Financial Friction and Investment Dynamics,

Giordani, P. and Soderlind, P. (2003). Inflation forecast uncertainty. European Economic Review, 47, 1037-1059.

Gregory, Krag and Rangel, Jose (2012), "Links between policy uncertainty and equity volatility", The Buzz, published by Goldman Sachs November 12, 2012.

Gulen, Huseyin and Ion, Mihai (2012), "Policy uncertainty and corporate investment", Purdue mimeo.

Handley, Kyle and Limao, Nuno (2012), "Trade and investment under policy uncertainty: theory and firm evidence", Maryland mimeo.

Hassett, Kevin A. and Gilbert E. Metcalf, 1999. "Investment with Uncertain Tax Policy: Does Random Tax Policy Discourage Investment?” Economic Journal, 109, no. 457 (July), 372-393. 
Higgs, Robert, 1997, "Why the Great Depression Lasted So Long and Why Prosperity Resumed After the War" The Independent Review, Vol 1, No. 4.

Joint Committee on Taxation, 2011. List of Expiring Tax Provisions, 2010-2020 (JCX-211), January 21, and similar documents for earlier years. Available at www.jct.gov.

Julio, Brandon and Youngsung Yook, 2010. "Political Uncertainty and Corporate Investment Cycles," Journal of Finance, forthcoming.

Panousi, Vasia and Papanikolaou, Dimitris (2011), "Investment, idiosyncratic risk and ownership", forthcoming Journal of Finance.

Pastor, Lubos and Veronesi, Pietro, (2011a), "Uncertainty about government policy and stock prices", forthcoming Journal of Finance.

Pastor, Lubos and Veronesi, Pietro, (2011b), "Political Uncertainty and Risk Premia," working paper, University of Chicago, September.

Rich, Robert and Tracy, Joseph. (2010), "The relationship among expected inflation, disagreement, and uncertainty: evidence from matched point and density forecasts", Review of Economic Studies, 92(1), 200-207.

Rodrik, Dani, 1991. "Policy Uncertainty and Private Investment," Journal of Development Economics, 36, 229-242.

Stock, James and Mark Watson. (2012): "Disentangling the Channels of the 2007-2009 Recession" Brookings Panel on Economic Activity.

Zarnowitz, Victor, and Louis A. Lambros, "Consensus and Uncertainty in Economic Prediction," Journal of Political Economy 95 (1987), 591-621. 
Table A1: Effects of Political Media Slant on News-Based Economic Policy Uncertainty

\begin{tabular}{|c|c|c|c|c|c|c|}
\hline Time period & $\begin{array}{c}\text { (1) } \\
\text { News Uncert }\end{array}$ & $\begin{array}{c}\text { (2) } \\
\text { News Uncert }\end{array}$ & $\begin{array}{c}(3) \\
\text { News Uncert }\end{array}$ & $\begin{array}{c}\text { (4) } \\
\text { News Uncert }\end{array}$ & $\begin{array}{c}(5) \\
\text { News Uncert }\end{array}$ & $\begin{array}{c}(6) \\
\log (\text { News Uncert })\end{array}$ \\
\hline $\begin{array}{l}\text { Media Slant } \\
\text { Media Slant* Dem. President } \\
\text { Media Slant* Dem. Congress }\end{array}$ & $\begin{array}{c}0.00132 \\
(0.045)\end{array}$ & $\begin{array}{c}0.831 \\
(2.862) \\
-1.94 \\
(6.661)\end{array}$ & $\begin{array}{c}2.105 \\
(3.036) \\
-3.237 \\
(6.808) \\
-3.416^{*} \\
(1.765) \\
\end{array}$ & $\begin{array}{l}-0.285 \\
(0.156) \\
0.700^{*} \\
(0.367\end{array}$ & $\begin{array}{c}-0.618 * * * \\
(0.173) \\
1.007 * * \\
(0.386) \\
0.839 * * * \\
(0.142) \\
\end{array}$ & $\begin{array}{c}0.0702 * \\
(0.0322) \\
-0.0841 \\
(0.0484) \\
-0.0247 \\
(0.0286) \\
\end{array}$ \\
\hline Observations & 3,299 & 3,299 & 3,299 & 3,299 & 3,299 & 3,299 \\
\hline $\mathrm{R}^{2}$ & 0.407 & 0.407 & 0.409 & 0.008 & 0.050 & 0.315 \\
\hline Year-Month Controls & YES & YES & YES & $\mathrm{NO}$ & $\mathrm{NO}$ & YES \\
\hline
\end{tabular}


Table 1: Determinants of Large Stock Market Movement, 1980-2011

\begin{tabular}{|c|c|c|c|c|c|c|c|c|c|c|}
\hline $\begin{array}{l}\text { Pre- and Post-Great } \\
\text { Recession }\end{array}$ & $\begin{array}{l}\text { Policy- } \\
\text { Related }\end{array}$ & Macroeconomic & Earnings & War/Terror & $\begin{array}{c}\text { Interest } \\
\text { Rates }\end{array}$ & Oil & Other & Unknown & Other & Total Events \\
\hline $1980-2007$ & $14 \%$ & $31 \%$ & $12 \%$ & $11 \%$ & $9 \%$ & $2 \%$ & $22 \%$ & $3 \%$ & $17 \%$ & 170 \\
\hline $2008-2011$ & $39 \%$ & $35 \%$ & $12 \%$ & $0 \%$ & $3 \%$ & $2 \%$ & $11 \%$ & $1 \%$ & $8 \%$ & 120 \\
\hline \multicolumn{11}{|l|}{ Recessions } \\
\hline 1981-1982 & $20 \%$ & $50 \%$ & $0 \%$ & $0 \%$ & $10 \%$ & $0 \%$ & $20 \%$ & $10 \%$ & $10 \%$ & 10 \\
\hline 1990-1991 & $0 \%$ & $9 \%$ & $9 \%$ & $73 \%$ & $9 \%$ & $0 \%$ & $0 \%$ & $0 \%$ & $0 \%$ & 11 \\
\hline 2001 & $0 \%$ & $36 \%$ & $21 \%$ & $14 \%$ & $14 \%$ & $0 \%$ & $14 \%$ & $0 \%$ & $14.3 \%$ & 14 \\
\hline
\end{tabular}

Notes: Source is the New York Times from the day after each large stock market movement. Large stock market movement is a move of more than $2.5 \%$. 
Table 2: The Intensity and Composition of Economic Policy Uncertainty in the News Index, by Time Period

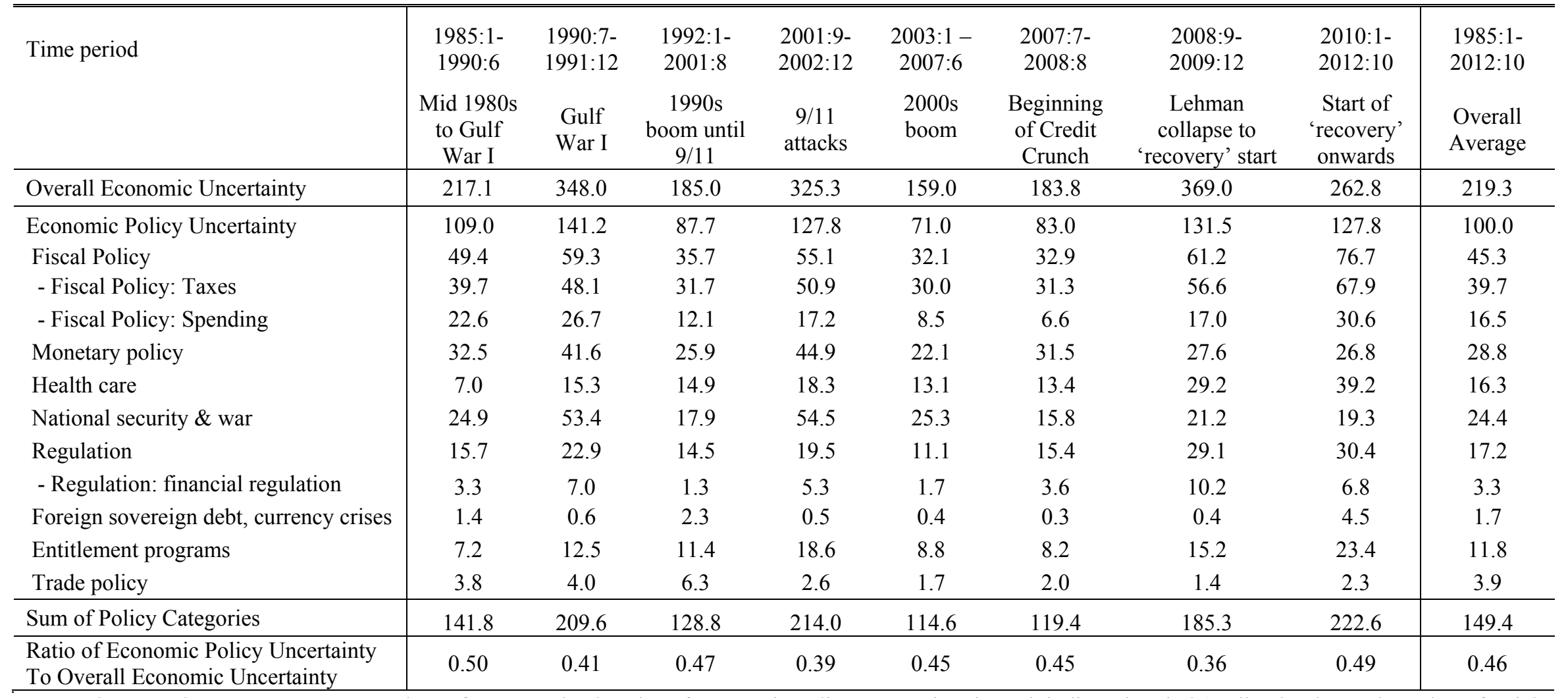

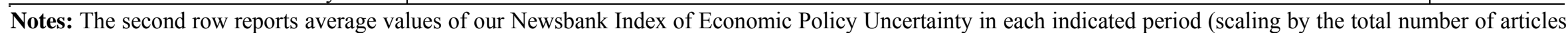

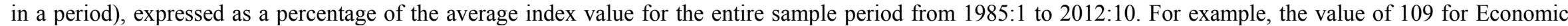

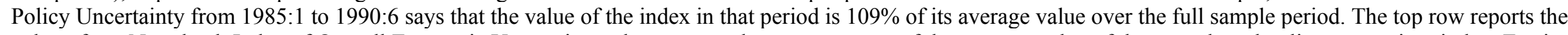

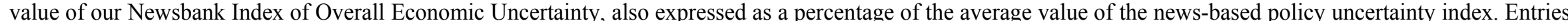

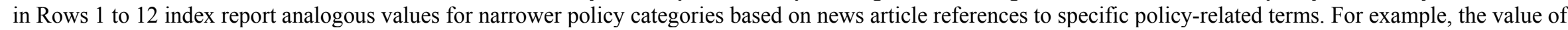

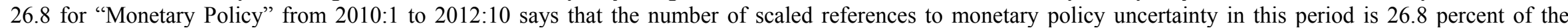

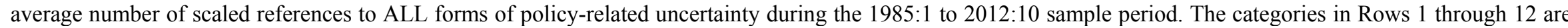

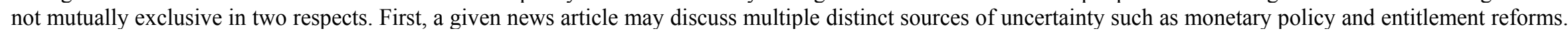

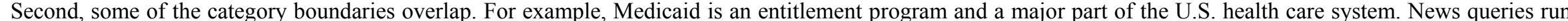
Nov 12, 2012. 


\section{Specific search terms by row:}

-Fiscal policy: "taxes" OR "tax" OR "taxation" OR "taxed" OR "government spending" OR "federal budget" OR "budget battle" OR "balanced budget" OR "defense spending” OR "military spending” OR "entitlement spending” OR "fiscal stimulus" OR "budget deficit” OR "federal debt" OR "national debt” OR "Gramm-Rudman" OR “debt ceiling” OR "fiscal footing” OR "government deficits" OR "balance the budget”;

-Monetary Policy: "federal reserve" OR "the fed” OR "money supply" OR "open market operations" OR "quantitative easing” OR "monetary policy" OR "fed funds rate" OR "overnight lending rate" OR "the fed" OR "Bernanke" OR "Volker" OR "Greenspan" OR "central bank" OR "interest rates" OR "fed chairman" OR "fed chair" OR "lender of last resort” OR "discount window" OR "European Central Bank" OR "ECB” OR "Bank of England” OR "Bank of Japan" OR "BOJ" OR "Bank of China" OR "Bundesbank" OR "Bank of France” OR "Bank of Italy";

-Health care: "health care" OR "Medicaid" OR "Medicare" OR "health insurance" OR "malpractice tort reform" OR "malpractice reform" OR "prescription drugs" OR "drug policy" OR "food and drug administration" OR "FDA" OR "medical malpractice" OR "prescription drug act" OR "medical insurance reform" OR "medical liability" OR "part d" OR "affordable care act" OR "Obamacare";

-National security and war: "”national security" OR "war" OR "military conflict" OR "terrorism” OR "terror" OR " $9 / 11$ " OR "defense spending" OR "military spending” OR "police action" OR "armed forces" OR "base closure” OR "military procurement" OR "saber rattling” OR "naval blockade" OR "military embargo" OR "no-fly zone" OR "military invasion";

-Regulation: "regulation" OR "banking supervision" OR “Glass-Steagall” OR “tarp” OR "bank supervision” OR “thrift supervision" OR "Dodd-frank" OR "financial reform" OR "commodity futures trading commission" OR "cftc" OR "house financial services committee" OR "Basel" OR "capital requirement" OR "Volcker rule" OR "bank stress test" OR "securities and exchange commission" OR "sec" OR "deposit insurance” OR "fdic" OR "fslic" OR "ots" OR "occ" OR "firrea" OR "truth in lending" OR "union rights" OR "card check" OR "collective bargaining law" OR "national labor relations board" OR "nlrd" OR "minimum wage" OR "living wage" OR "right to work" OR "closed shop" OR "wages and hours" OR "workers compensation" OR "advance notice requirement” OR “affirmative action” OR “at-will employment” OR “overtime requirements” OR "trade adjustment assistance” OR “davis-bacon” OR “equal

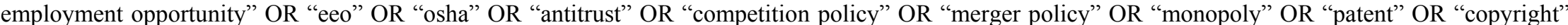
OR "federal trade commission" OR "ftc" OR "unfair business practice” OR "cartel” OR "competition law" OR "price fixing” OR "class action" OR "healthcare lawsuit" OR "tort reform" OR "tort policy" OR "punitive damages" OR "medical malpractice" OR "energy policy" OR "energy tax" OR "carbon tax" OR "cap and trade" OR "cap and tax" OR "drilling restrictions" OR "offshore drilling" OR "pollution controls" OR "environmental restrictions" OR "clean air act” OR "clean water act” OR "environmental protection agency" OR "epa” OR "immigration policy";

-Foreign sovereign debt and currency crisis: "sovereign debt" OR "currency crisis" OR "currency crash" OR "currency devaluation" OR "currency revaluation" OR “currency manipulation" OR "euro crisis" OR "Eurozone crisis" OR "european financial crisis" OR “european debt” OR “asian financial crisis" OR "asian crisis" OR "Russian financial crisis" OR "Russian crisis" OR "exchange rate";

-Entitlement programs: "entitlement program” OR “entitlement spending” OR "government entitlements" OR "social security” OR "Medicaid” OR "medicare" OR "government welfare" OR "welfare reform" OR "unemployment insurance" OR "unemployment benefits" OR "food stamps" OR "afdc" OR "tanf” OR "wic program” OR "disability insurance” OR "part d" OR "oasdi” OR "Supplemental Nutrition Assistance Program" OR "Earned Income Tax Credit” OR "EITC” OR "head start program” OR "public assistance” OR "government subsidized housing”;

-Trade policy: "import tariffs" OR "import duty" OR "import barrier" OR "government subsidies" OR "government subsidy" OR "wto" OR "world trade organization" OR "trade treaty” OR "trade agreement” OR "trade policy” OR "trade act” OR “doha round” OR "uruguay round” OR “gatt” OR "dumping”;

\section{The authors welcome suggestions for improving the foregoing category-specific search terms.}


Table 3. Frequency of Discussions about Uncertainty in FOMC Beige Books, Counts By Policy Category and Overall

\begin{tabular}{|c|c|c|c|c|c|c|c|c|}
\hline Time period & $\begin{array}{l}\text { 1990Q4- } \\
\text { 1991Q1 } \\
\text { Gulf War I }\end{array}$ & $\begin{array}{l}\text { 1993Q2- } \\
\text { 1993Q3 } \\
\text { Clinton tax } \\
\text { reforms }\end{array}$ & $\begin{array}{c}\text { 2001Q4- } \\
\text { 2002Q2 } \\
9 / 11 \\
\text { attacks }\end{array}$ & $\begin{array}{l}\text { 2002Q4- } \\
\text { 2003Q2 } \\
\text { Gulf War II }\end{array}$ & $\begin{array}{c}\text { 2004Q2- } \\
\text { 2004Q4 } \\
\text { Bush/Kerry } \\
\text { Election }\end{array}$ & $\begin{array}{l}\text { 2008Q3- } \\
\text { 2009Q4 } \\
\text { Lehman's and } \\
\text { recession }\end{array}$ & $\begin{array}{l}\text { 2010Q1- } \\
\text { 2012Q4 } \\
\text { Debt-ceiling } \\
\quad \text { crisis }\end{array}$ & $\begin{array}{l}\text { 1983Q3- } \\
\text { 2012Q4 } \\
\text { Overall } \\
\text { Average }\end{array}$ \\
\hline Overall Economic Uncertainty & 11 & 8.8 & 7.7 & 13.5 & 5.2 & 10.2 & 15.3 & 5.28 \\
\hline Economic Policy Uncertainty & 5.5 & 6.3 & 1.2 & 4.8 & 2.8 & 0.8 & 6.3 & 1.49 \\
\hline Fiscal Policy & 1 & 5.5 & 1.5 & 0 & 0 & 0.4 & 3.4 & 0.74 \\
\hline - Fiscal Policy: Taxes & 0 & 3.3 & 0.2 & 0 & 0 & 0.3 & 1.0 & 0.27 \\
\hline - Fiscal Policy: Spending & 0.5 & 1 & 1 & 0 & 0 & 0.2 & 0.8 & 0.23 \\
\hline Monetary Policy & 0 & 0 & 0 & 0 & 0 & 0 & 0 & 0 \\
\hline Health Care & 0 & 2 & 0 & 0 & 0 & 0.2 & 0.5 & 0.13 \\
\hline National Security \& War & 5.3 & 0.3 & 0 & 2 & 0 & 0 & 0.1 & 0.20 \\
\hline Regulation (All Financial Regulation) & 0 & 0 & 0 & 0 & 0 & 0.2 & 1.3 & 0.16 \\
\hline Foreign sovereign debt, currency crisis & 0 & 0 & 0 & 0 & 0 & 0 & 0.8 & 0.09 \\
\hline U.S. Elections \& Leadership Changes & 0 & 0 & 0 & 0.2 & 2.2 & 0 & 1.0 & 0.20 \\
\hline Other Specified Policy Matters & 0 & 0.5 & 0.7 & 0 & 0 & 0 & 0.6 & 0.17 \\
\hline Politics, Unspecified & 0.5 & 1.0 & 0 & 3.0 & 0.7 & 0 & 1.4 & 0.29 \\
\hline Sum of Policy Categories & 6.8 & 9.5 & 2.2 & 5.2 & 3.1 & 0.9 & 9.1 & 1.97 \\
\hline
\end{tabular}

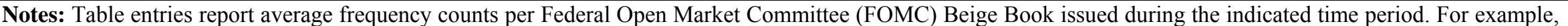

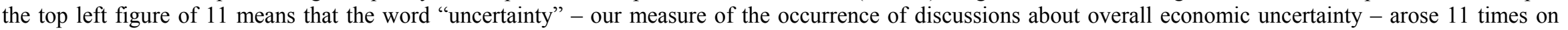
average in the Beige Book during 1990Q4-1991Q1. The Beige Book is typically released two weeks before regularly scheduled FOMC meetings, which occur about once every six weeks. The first FOMC Beige Book was issued in the third quarter of 1983. Frequency counts are classified into policy categories based on human readings of the text surrounding each discussion of "uncertainty" in FOMC Beige Books. "Other Specified Policy Matters" covers legal policy, trade policy, labor regulations, environmental regulations, and elections and leadership changes abroad. "Politics, Unspecified" covers generic references to "politics" and "political" concerns that do not mention a specific policy or political matter. The sum of policy categories can exceed the count of "All Policy \& Politics" because some Beige Book discussions of uncertainty reference more than one policy-related source of uncertainty. 


\section{Figure 1: Index of Economic Policy Uncertainty}

\section{(Jan 1985 - Nov 2012)}

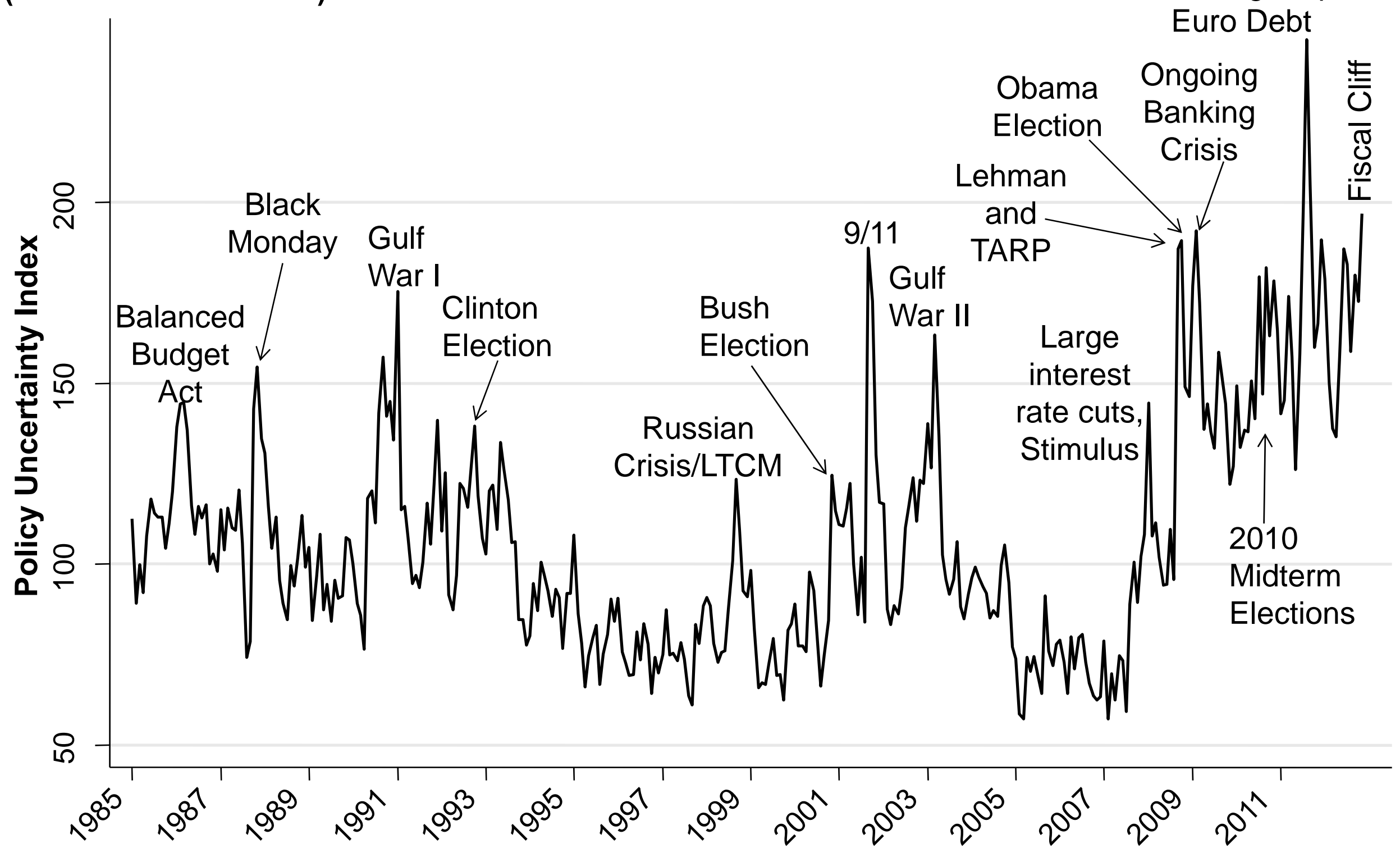

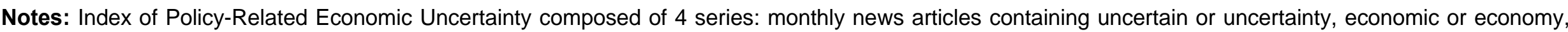

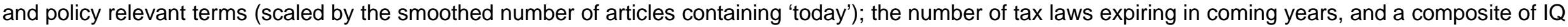

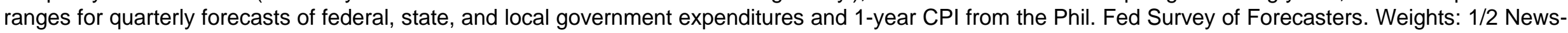

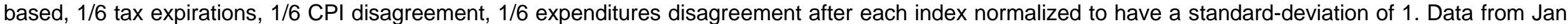
1985-Nov 2012. Index normalized mean 100 from 1985-2009. Data at www.policyuncertainty.com 
Figure 2: News-Based Policy Uncertainty Index

(Jan 1985 - Nov 2012)

Debt

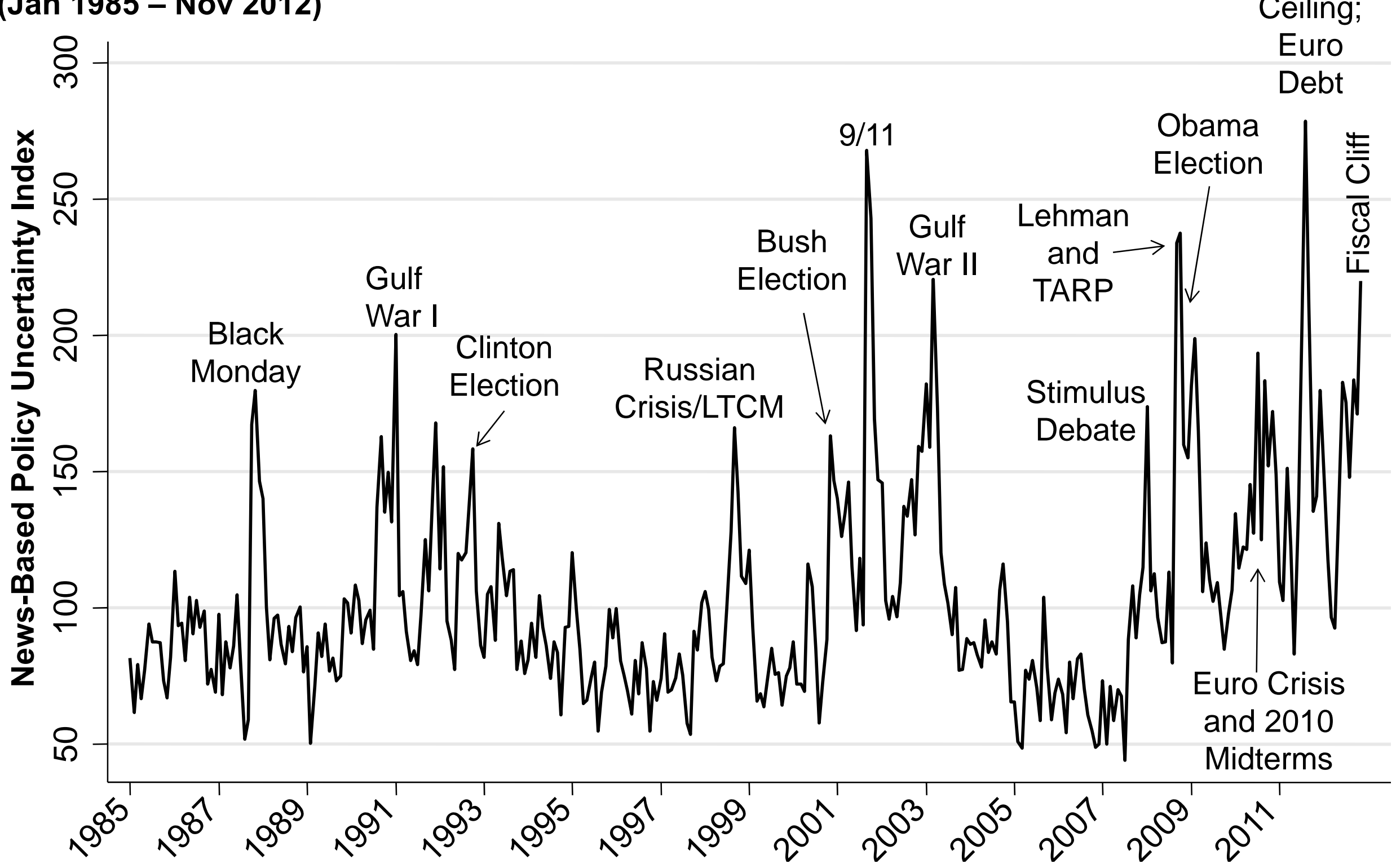

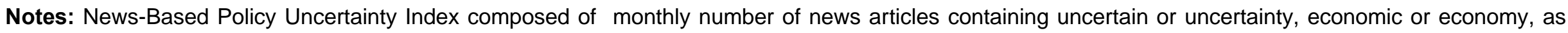

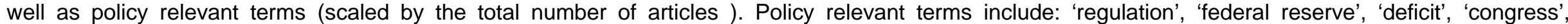

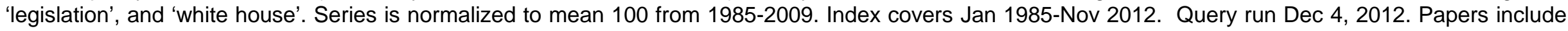

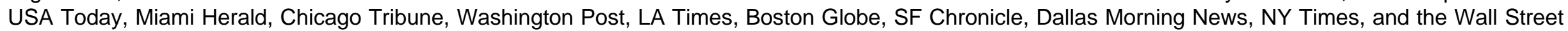
Journal. 


\section{Figure 3: Federal Tax Code Expiration Index}

\section{$(1991$ - 2012)}

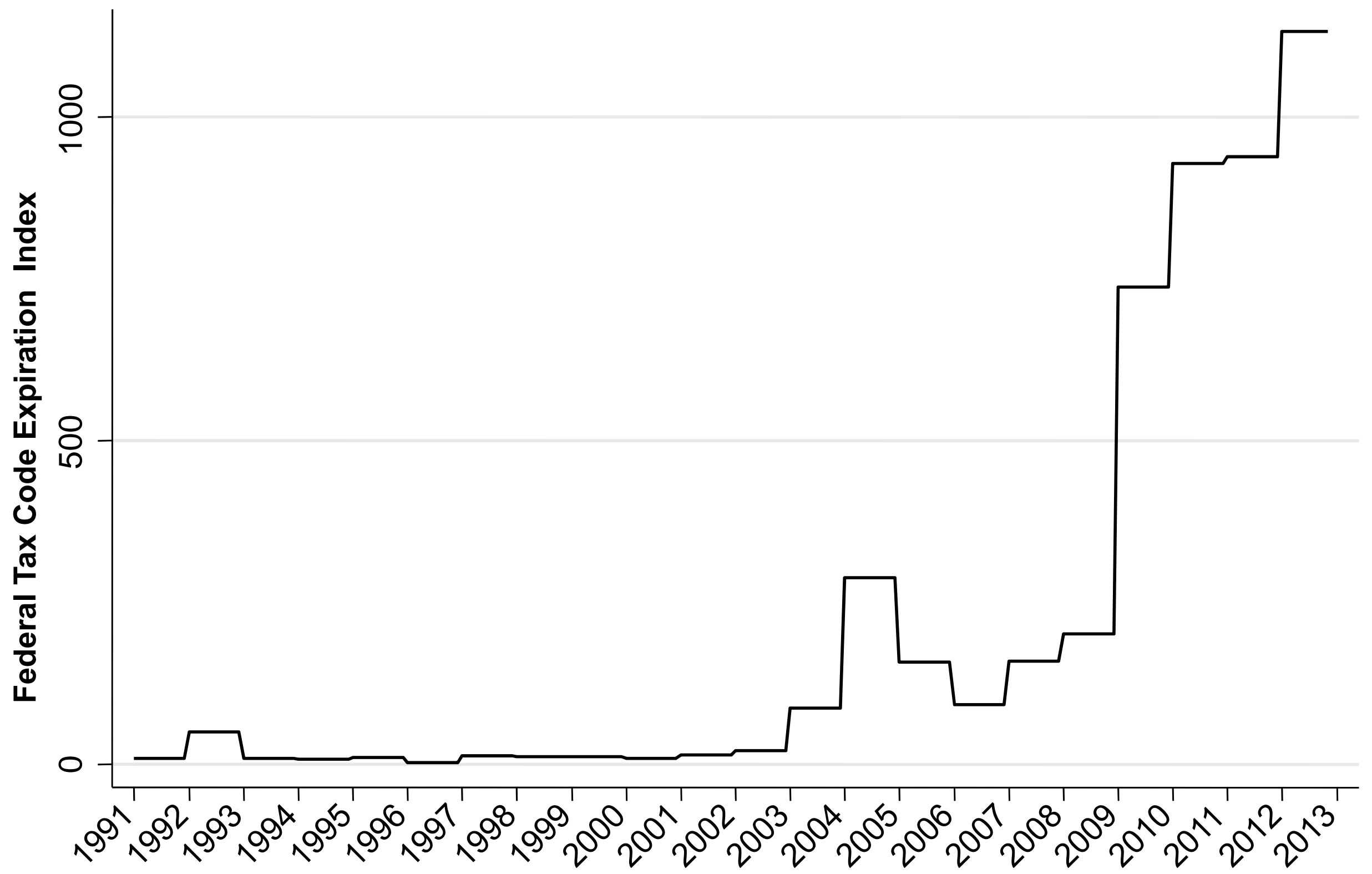

Notes: Utilizes List of Tax Expirations from the Congressional Budget Office. Each year's forecast is a 10-year horizon dollar-weighted sum of expiring tax dollars. Future years expirations are weighted by $0.5^{\wedge}((T+1))$ where $T$ is the number of years in the future the tax is expiring. Set to mean 100 prior to 2009 . The bump in 2002 to 2004 are the temporary accelerated depreciation allowances introduced in 2002. 
Figure 4: Federal, State, and Local Purchases Forecast Interquartile Range Index (Q1 1985 - Q4 2012)

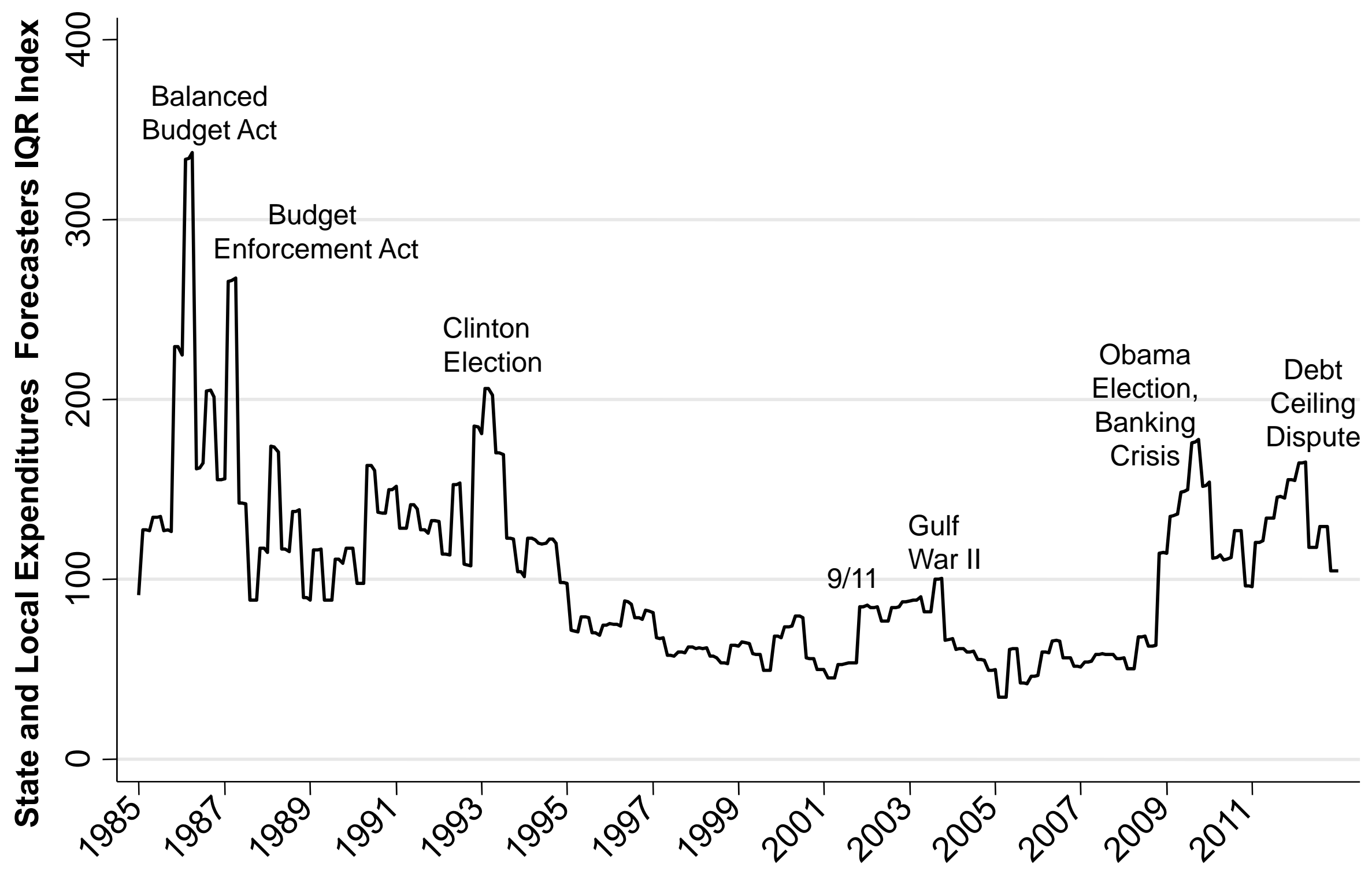

Notes: From the Philadelphia Federal Reserve Survey of Professional Forecasters. Takes the interquartile (IQ) range of the 1-year ahead forecasts (made every quarter; offset one month due to release dates such that Q4 covers Nov-Jan) of total Federal government purchases of goods and services and those of State and local government purchases relative to the mean forecast. Two series are added together weighted by relative size. Normalized to a mean 100 from 1985-2009. 
Figure 5: CPI Forecaster Interquartile Range, Percentage-Point Spread (Q1 1985 - Q4 2012)

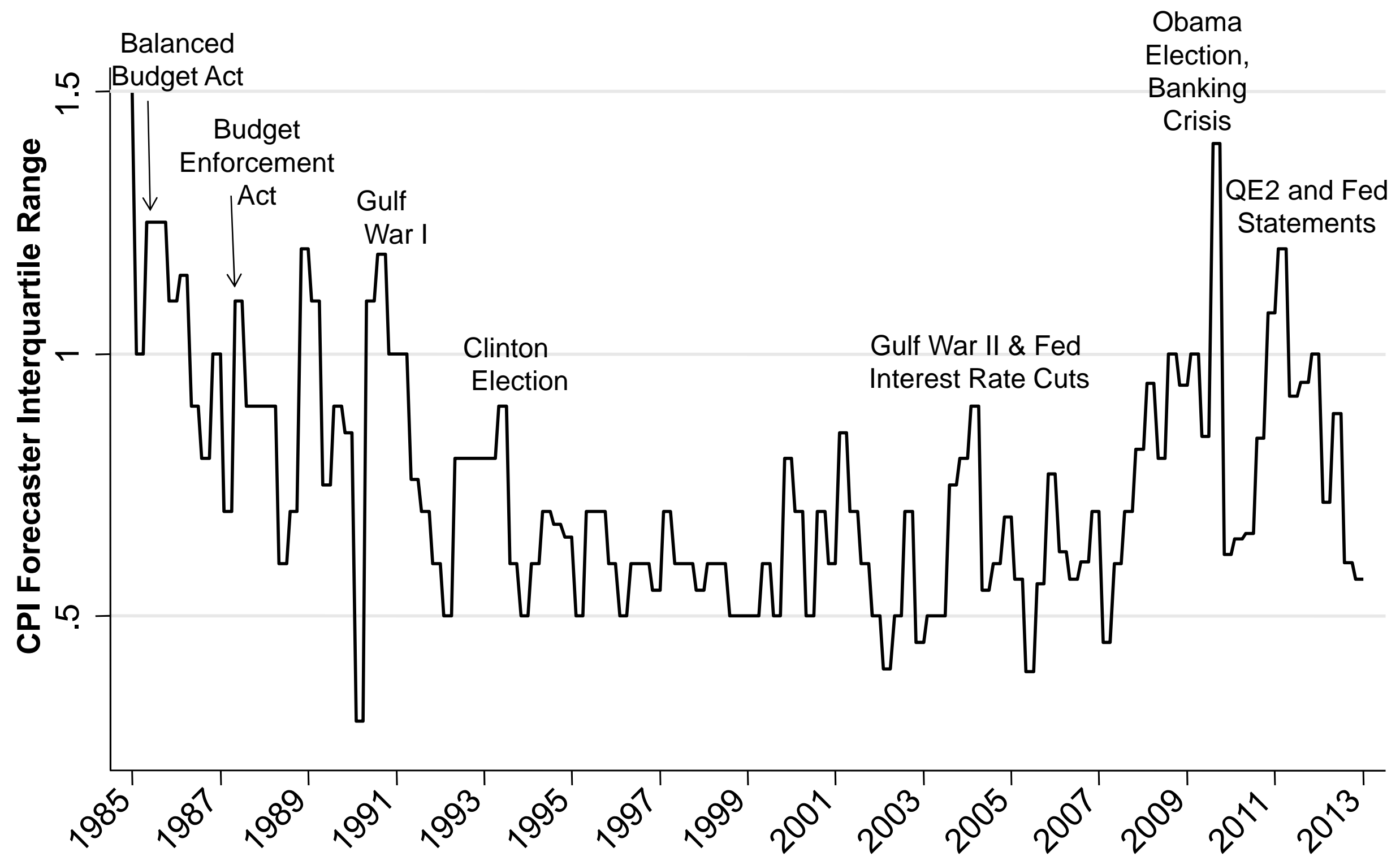

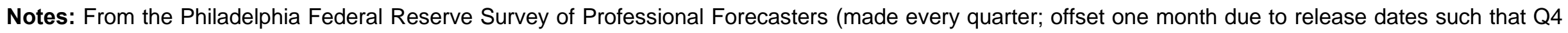
covers Nov-Jan. Displays the Interquartile (IQ) range of the quarterly 1-year-ahead forecasts of CPI. 
Figure 6: European Policy Uncertainty Index (Jan 1997 - Nov 2012)

Papandreou

calls for

referendum;

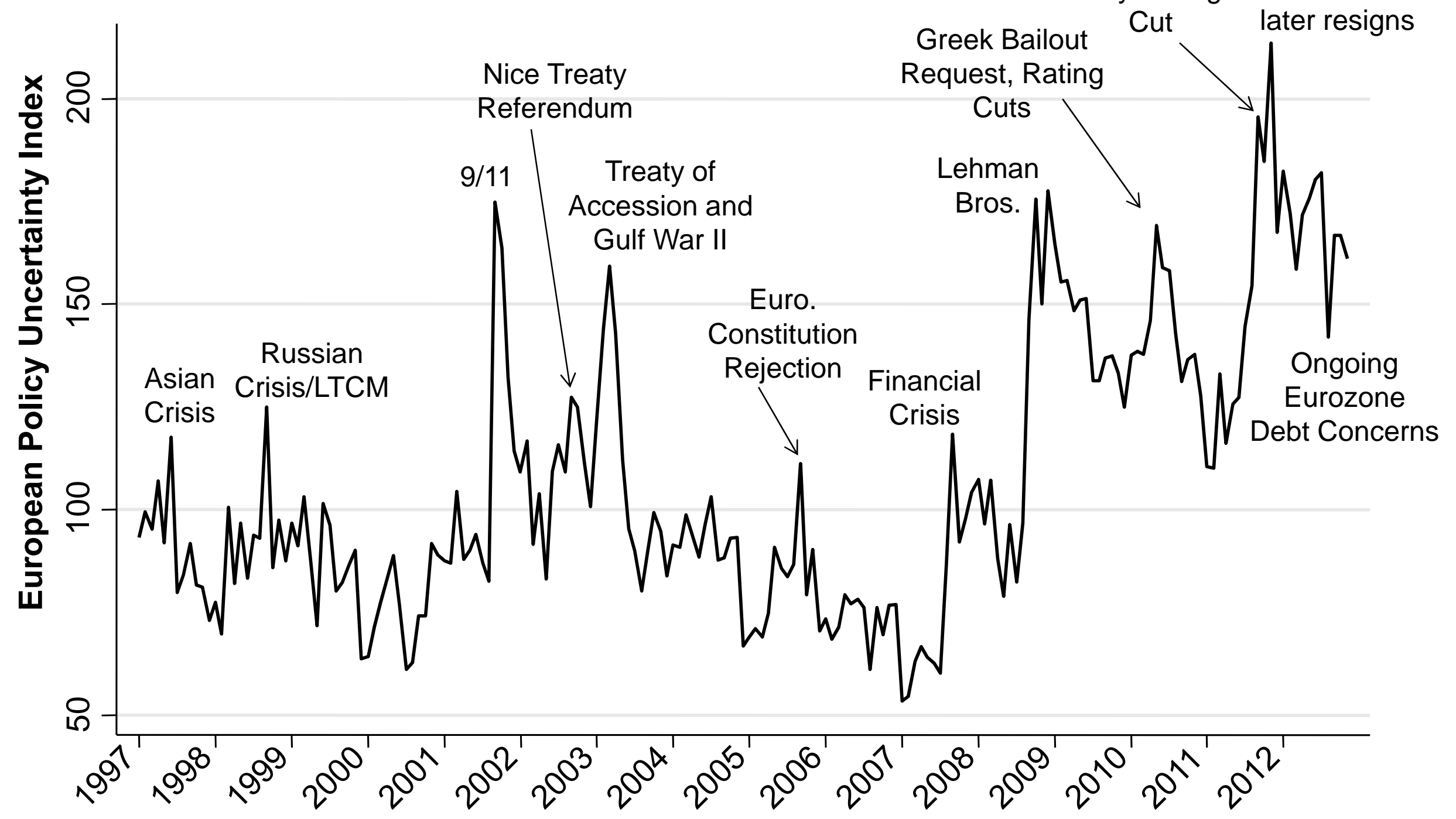

Notes: Index composed of a News-Based Index (0.5 weight), and country-level components measuring forecaster disagreement about inflation rates and federal government budget balance (each 0.25 weight). News-Based component composed of the monthly number of news articles containing uncertain or uncertainty, economic or economy, as well as policy relevant terms (scaled by the smoothed number of articles containing 'today'). Policy relevant terms include: 'policy', 'tax', 'spending', 'regulation', 'central bank', 'budget', and 'deficit'. Series is normalized to mean 100 from 1997-2010. Index covers Jan 1997 Nov 2012. Papers include El Pais, El Mundo, Corriere della Sera, La Repubblica, Le Monde, Le Figaro, Financial Times, The Times, Handelsblatt, FAZ. All searches done in the native language of the paper in question. 


\section{Figure 7: False positive and negative error rates for 28,000 permutations of 12 policy terms in an audit sample of size 3,500 articles}

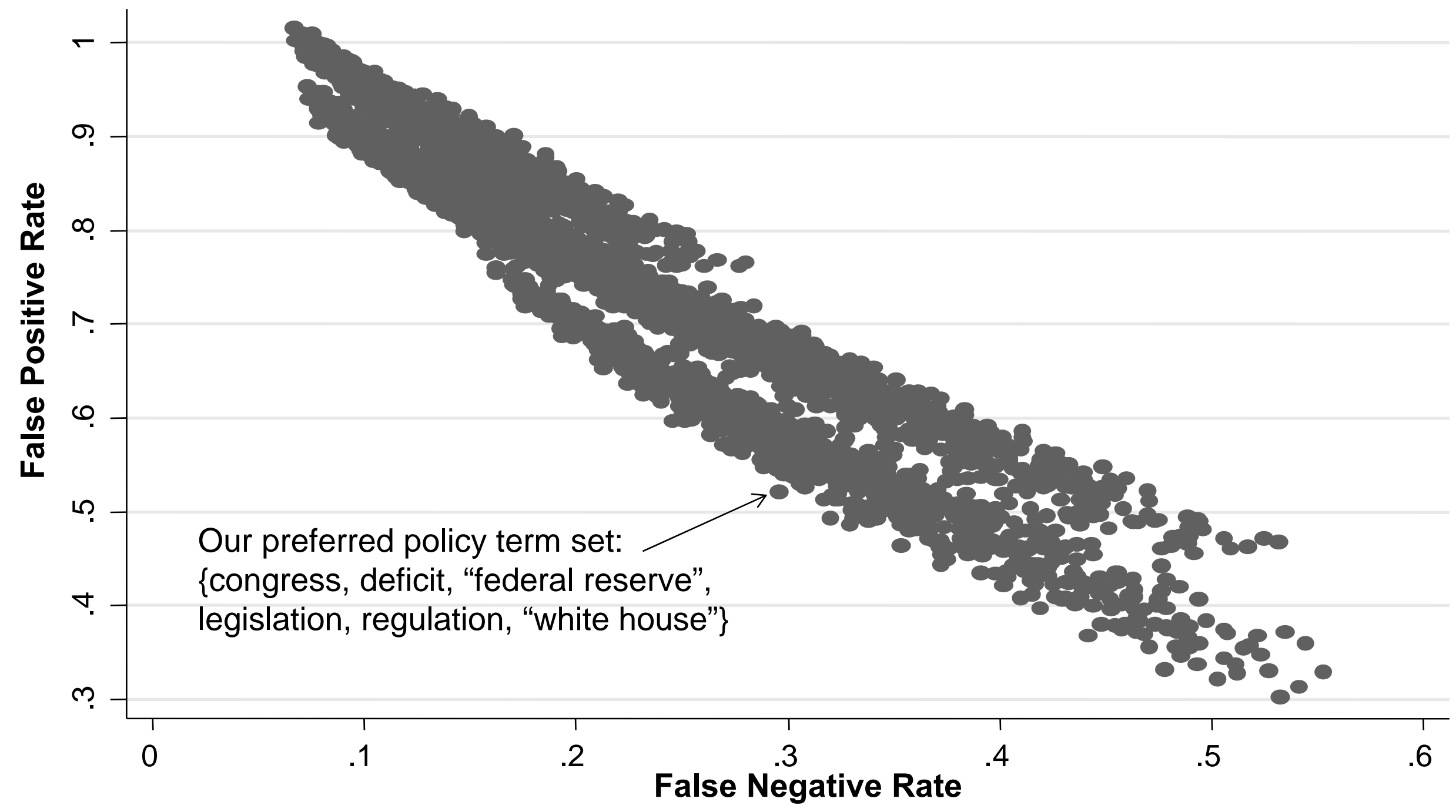

Note: Each data point shows error rates for a given combination of 4 or more policy terms drawn from the set: \{regulation, budget, deficit, tax, "federal reserve", government, congress, senate, president, legislation, "government spending", "federal spending"\}. Errors identified by comparing automated classifications to those produced by human readers. A False Positive occurs when EPU=1 by the automated method and EPU $=0$ according to the human reading. A False Negative occurs when EPU=0 by the automated method and EPU=1 according to the human reading. To express the error counts as rates, we scale by the true EPU count, i.e. by the number of EPU=1 designations according to the human readings. 
Figure 8: The frequency of the word "uncertainty" and the word "uncertainty" in a policy context in the FOMC's Beige Book have both risen since the recession of 2007-2009. (1983Q4 - 2012Q4)

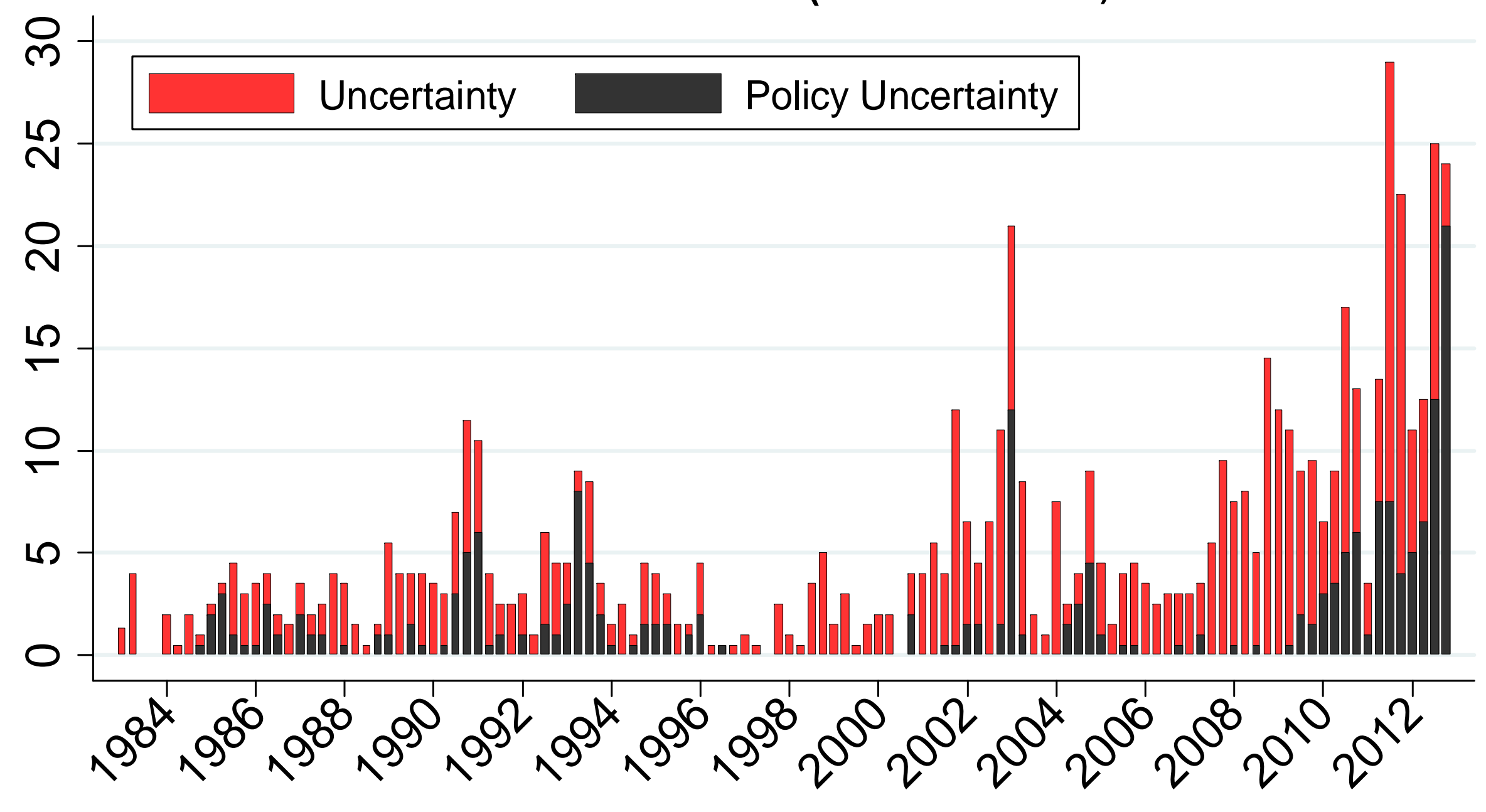

Note: Plots the frequency of the word "uncertain" in each quarter of the Federal Open Market Committees' (FOMC) Beige Book. The Beige Book is an overview of economic conditions of about 15,000 words in length prepared two weeks before each FOMC meeting. The count of "Policy Uncertainty" uses a human audit to attribute each mention of the word uncertain to a policy context (e.g. uncertainty about fiscal policy) or a non-policy context (e.g. uncertainty about GDP growth). See the paper for full details, 
Figure 9: Political slant has little impact on movements in our EPU index

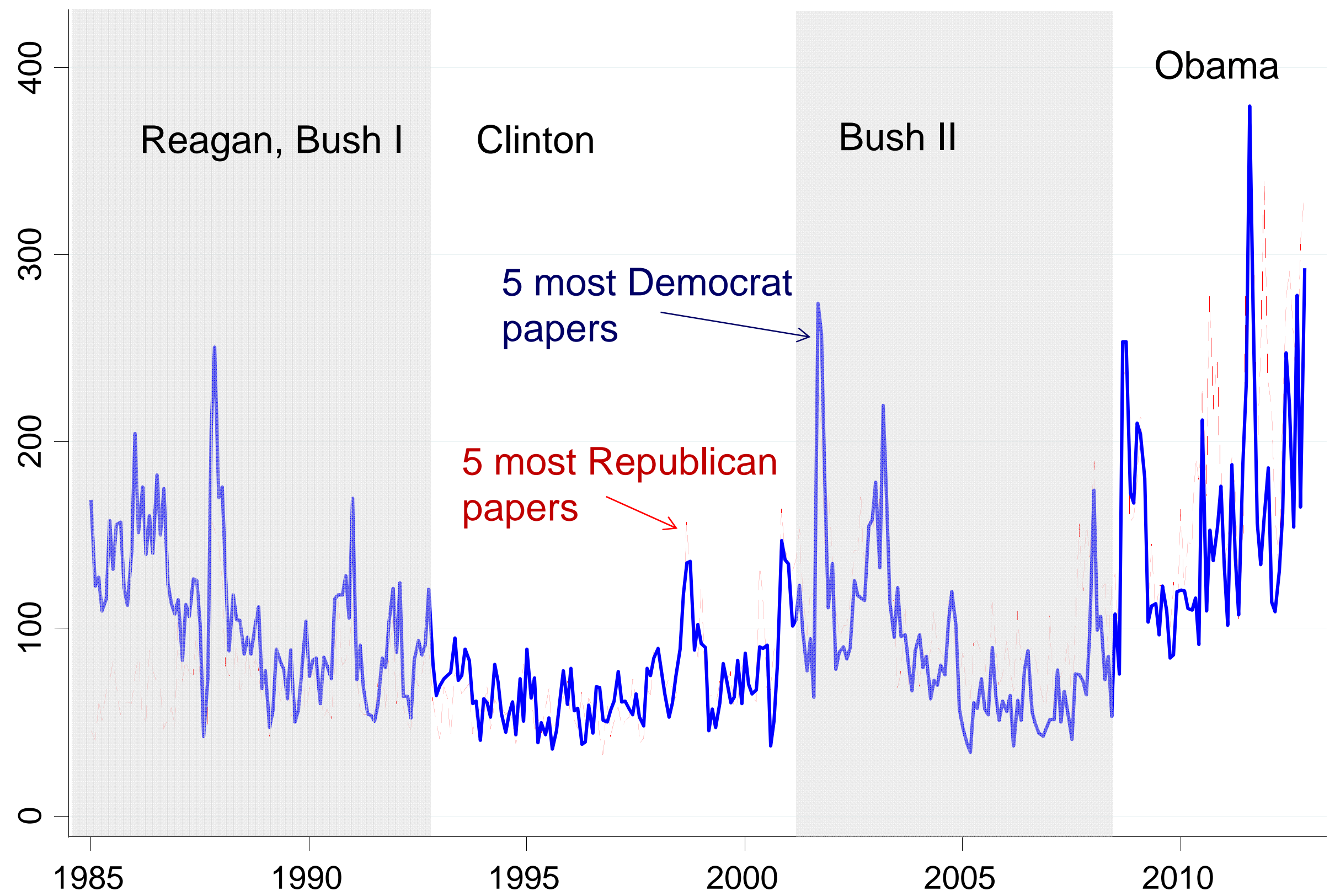

Source: Papers sorted into 5 most 'Republican' and 5 most 'Democratic' groups using the media slant measure from Gentzkow and Shapiro (2010). 
Figure 10: The VIX is moderately correlated with the US EPU Index

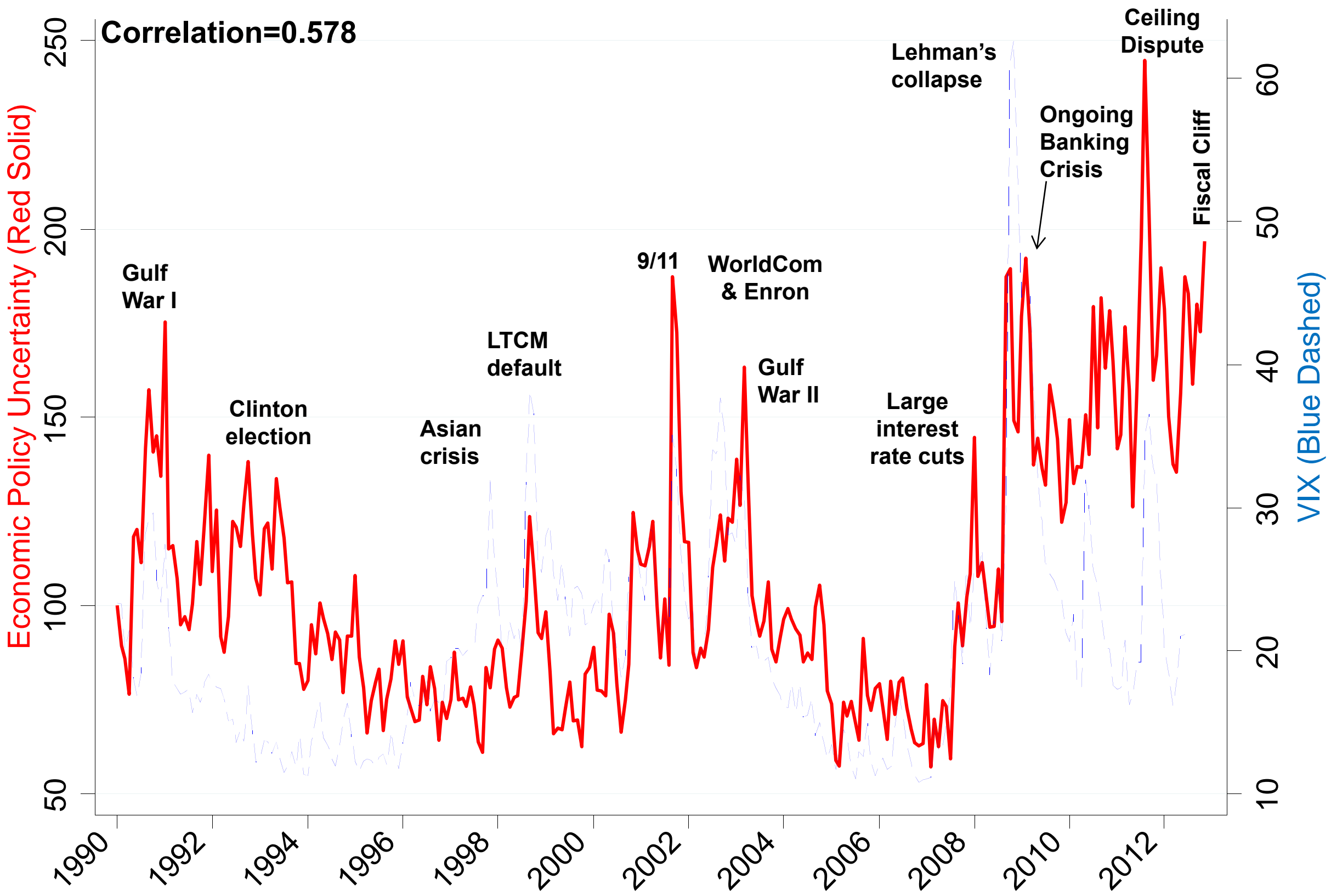

Source: The VIX comes from the Chicago Board Options Exchange. Economic Policy Uncertainty Index is the overall EPU index from Baker, Bloom, and Davis. Plotted until November 2012. 


\section{Figure 11: The VIX is highly correlated with a news index of equity market}

\section{uncertainty}

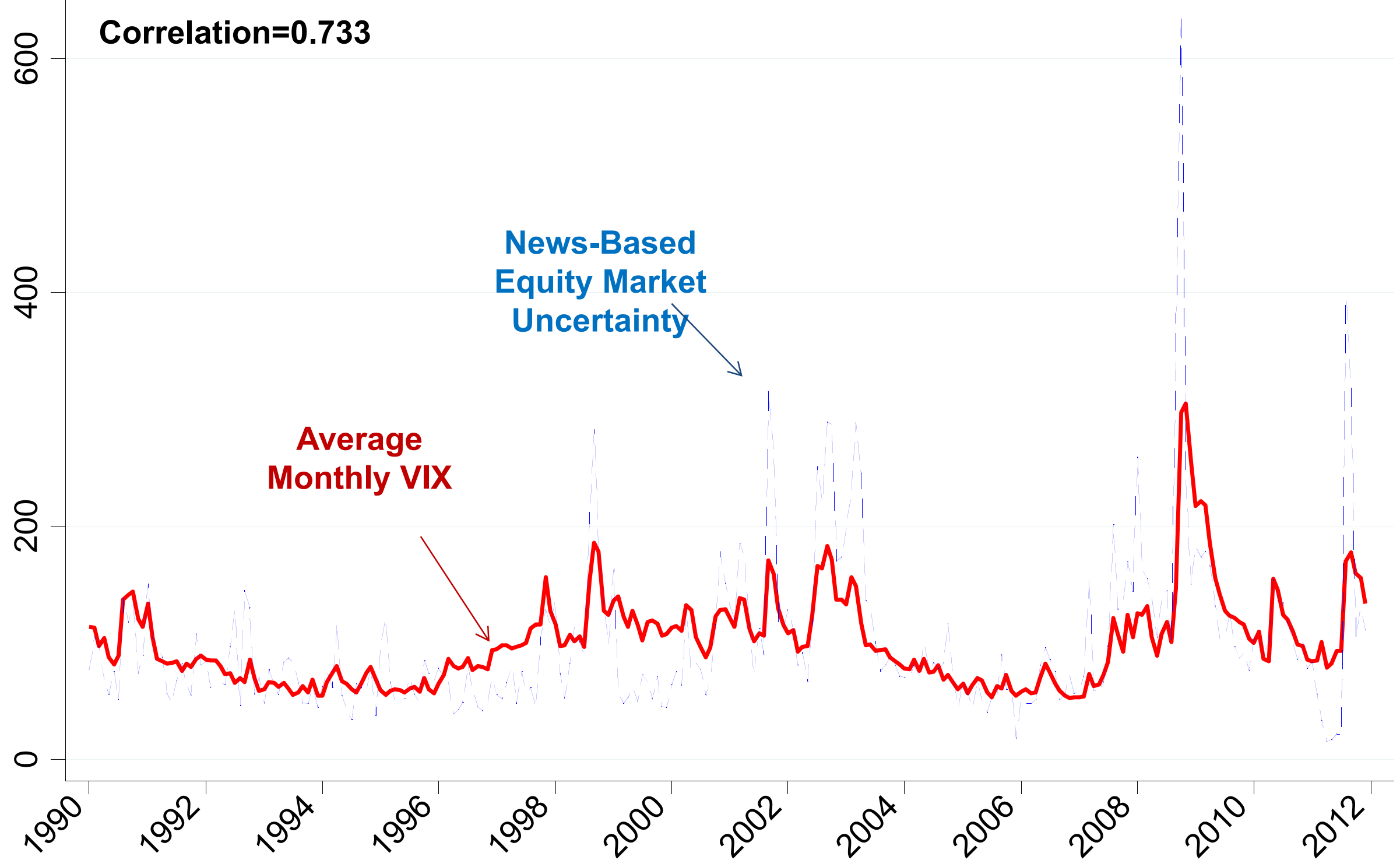

Notes: Frequency of the triple of "economy/economic", "uncertain/uncertainty" and one of a collection of financial market terms (stock price, equity price, stock market) in 10 major US papers and normalized by the total number of articles, by month and paper. Both series scaled to same mean. Each series set to mean of 100 over entire period. 
Figure 12: Estimated Industrial Production and Employment after a Policy Uncertainty Shock

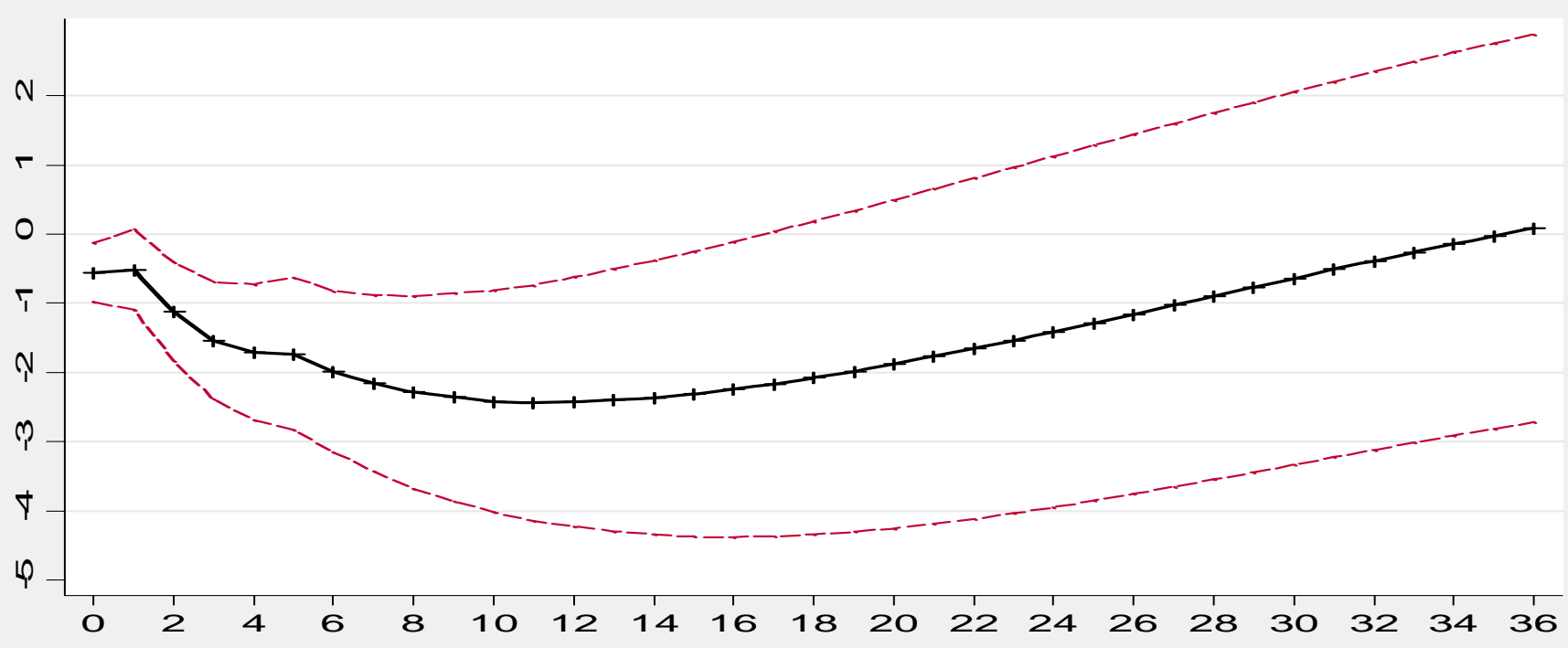

Notes: This shows the impulse response function for Industrial Production and employment to an 112 unit increase in the policy-related uncertainty index, the increase from 2006 (the year before the current crisis) to 2011. The central (black) solid line is the mean estimate while the dashed (red) outer lines are the onestandard-error bands. Estimated using a monthly Cholesky Vector Auto Regression (VAR) of the uncertainty index, $\log (\mathrm{S} \& \mathrm{P} \quad 500$ index) federal reserve funds rate, log employment, log industrial production and time trend. Data from 1985 to 2011.

Months after the economics policy uncertainty shock 


\section{Figure 13: Robustness of Estimates to Different VAR Specifications}

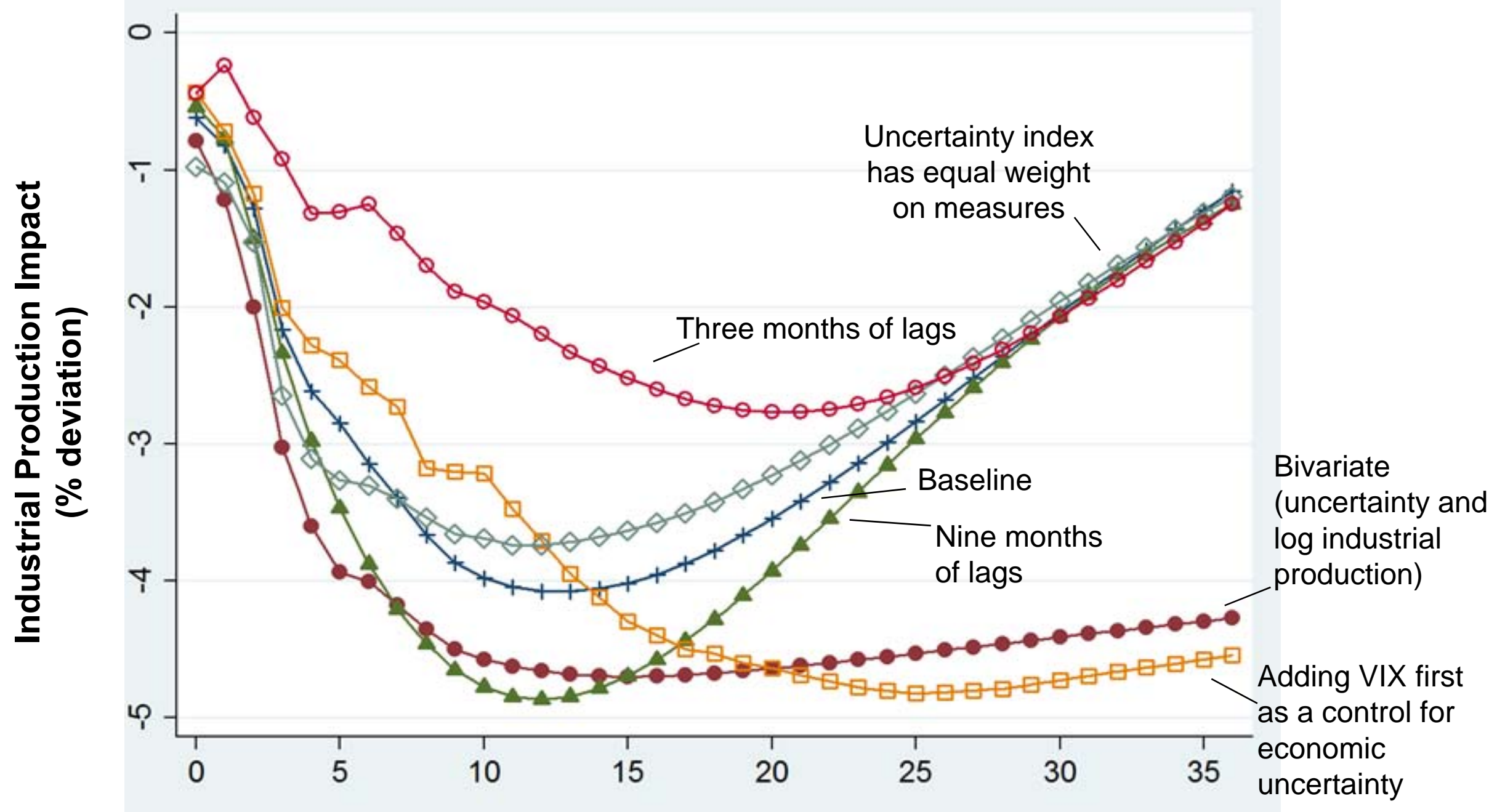

Months after the policy uncertainty shock

Notes: This shows the impulse response function for GDP and employment to an 112 unit increase in the policy-related uncertainty index. Estimated using a monthly Cholesky Vector Auto Regression (VAR) of the uncertainty index, log(S\&P 500 index), federal reserve funds rate, log employment, log industrial production and time trend unless otherwise specified. Data from 1985 to 2011. 


\section{Figure 14: Quarterly VAR estimates for GDP and investment}

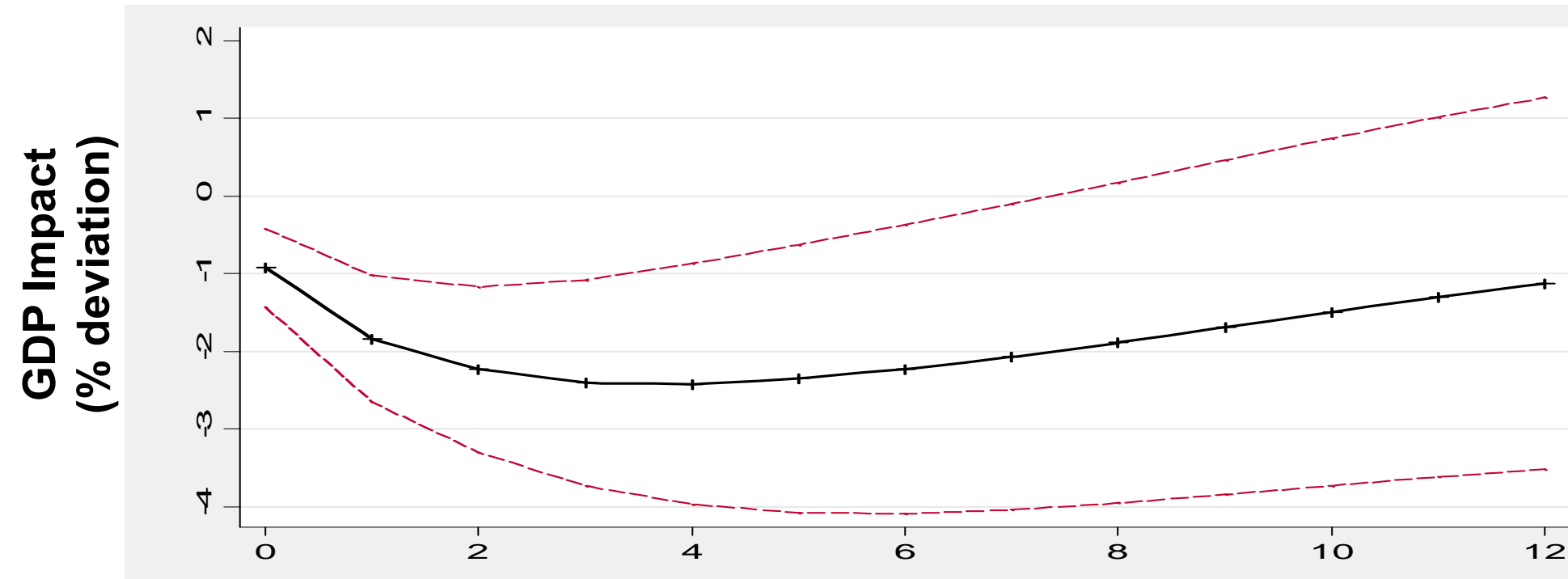

Notes: Shows the impulse response function to an 112 unit increase in the policyrelated uncertainty index, the increase from 2006 (the year before the current crisis) until 2011. The central (black) solid line is the mean estimate while the dashed (red) outer lines are the one-standard-error

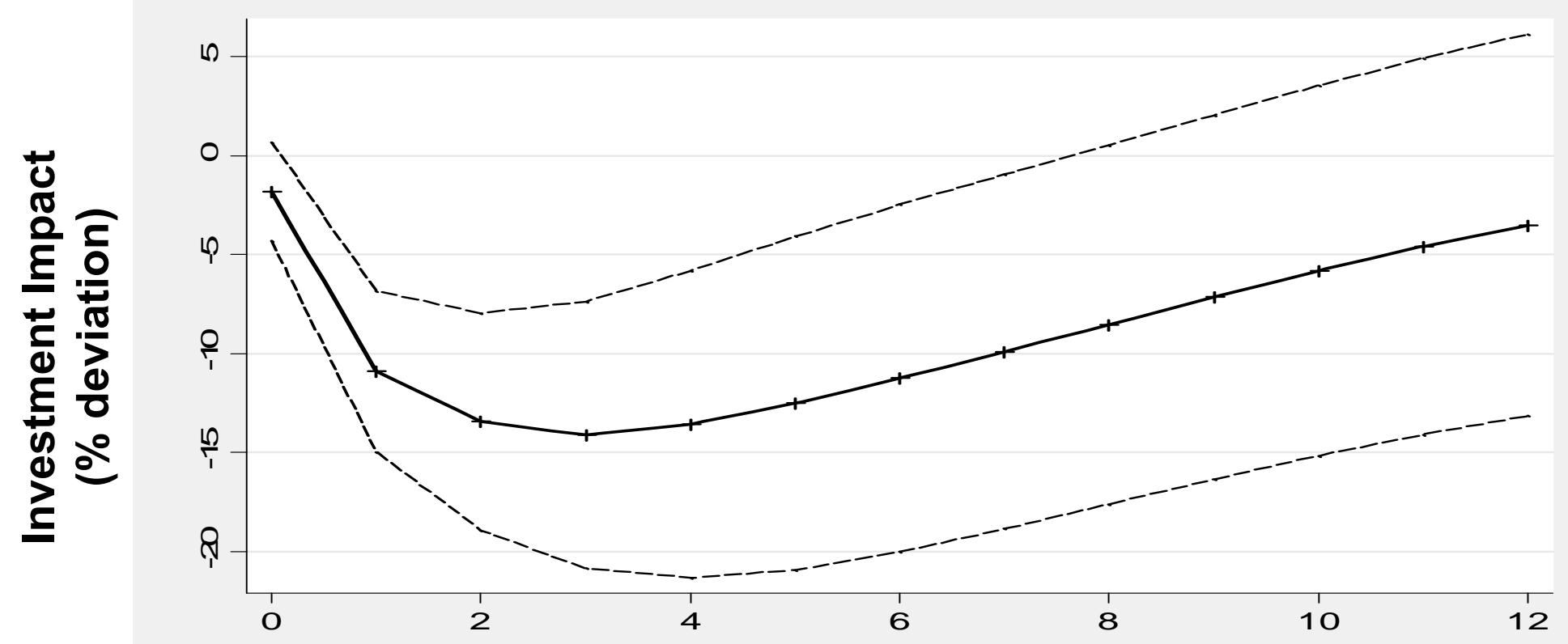

bands. VAR is estimated using a quarterly Cholesky VAR: the uncertainty index, $\log ($ S\&P 500 index), federal reserve funds rate, log employment, log investment, log consumption and log GDP. Data from 1985 to 2011.

Quarters after the policy uncertainty shock 


\section{Figure 15: Estimates after including controls for consumer confidence}

Consumer confidence included second in the VAR

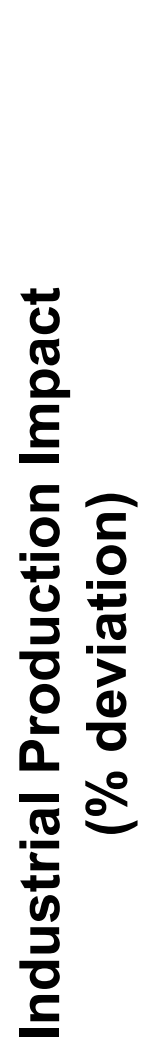

Consumer confidence included first in the VAR
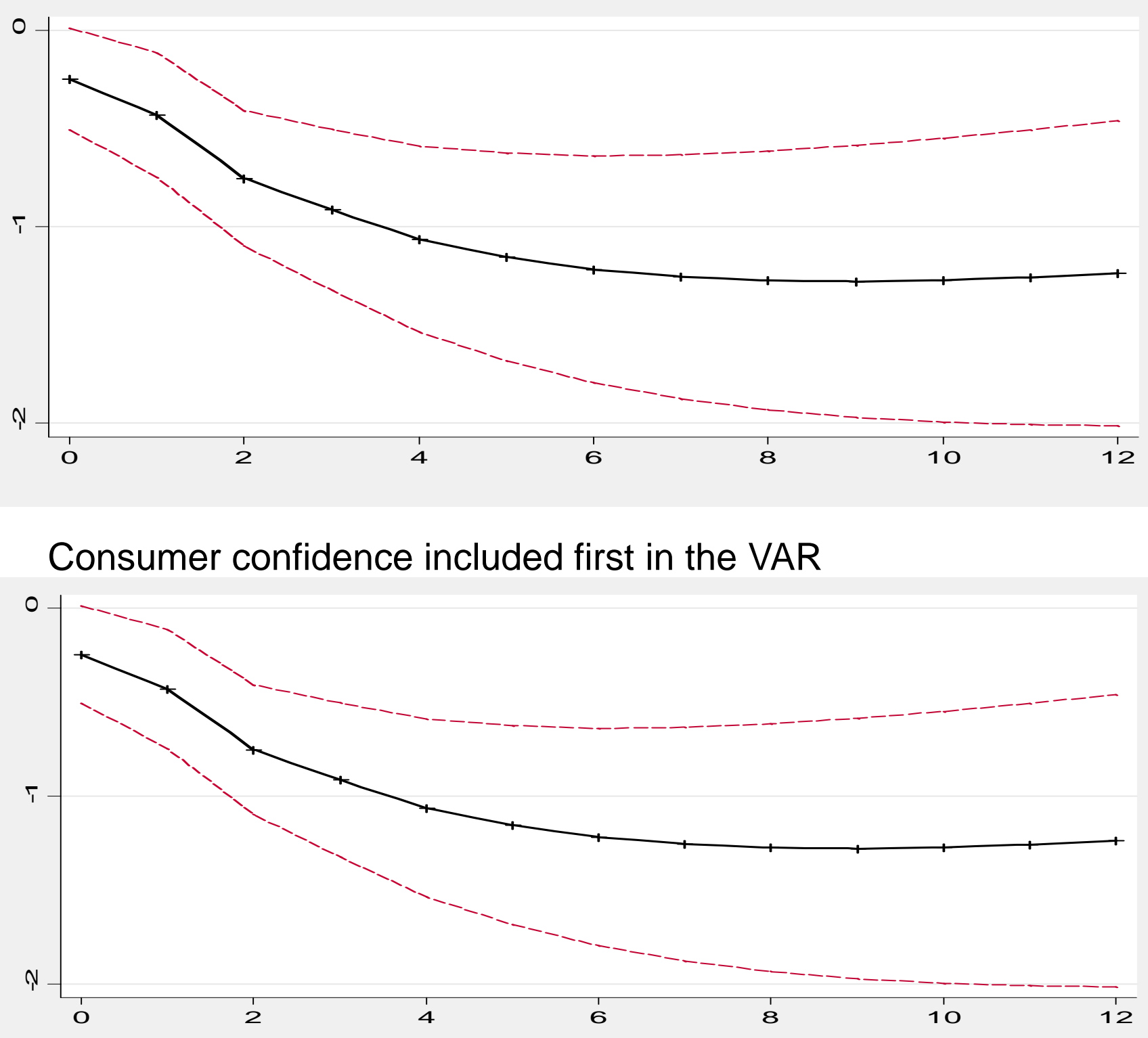

Notes: This shows the impulse response function for Industrial Production and employment to an 112 unit increase in the policy-related

uncertainty index, the increase from 2006 (the year before the current crisis) until 2011. The central (black) solid line is the mean estimate while the dashed (red) outer lines are the onestandard-error bands. Estimated using a monthly Cholesky Vector Auto Regression (VAR) of the uncertainty index, $\log (S \& P 500$ index), federal reserve funds rate, log employment, $\log$ industrial production and time trend. Data from 1985 to 2011. Top panel includes the Michigan Consumer confidence index included as the second variable after our uncertainty index, and the bottom panel includes the Michigan Consumer Confidence index included as the first variable.

Months after the economics policy uncertainty shock 


\section{Appendix Figure A1: Baseline EPU Index, Equal-Weighted EPU Index, PCF-Weighted EPU Index}

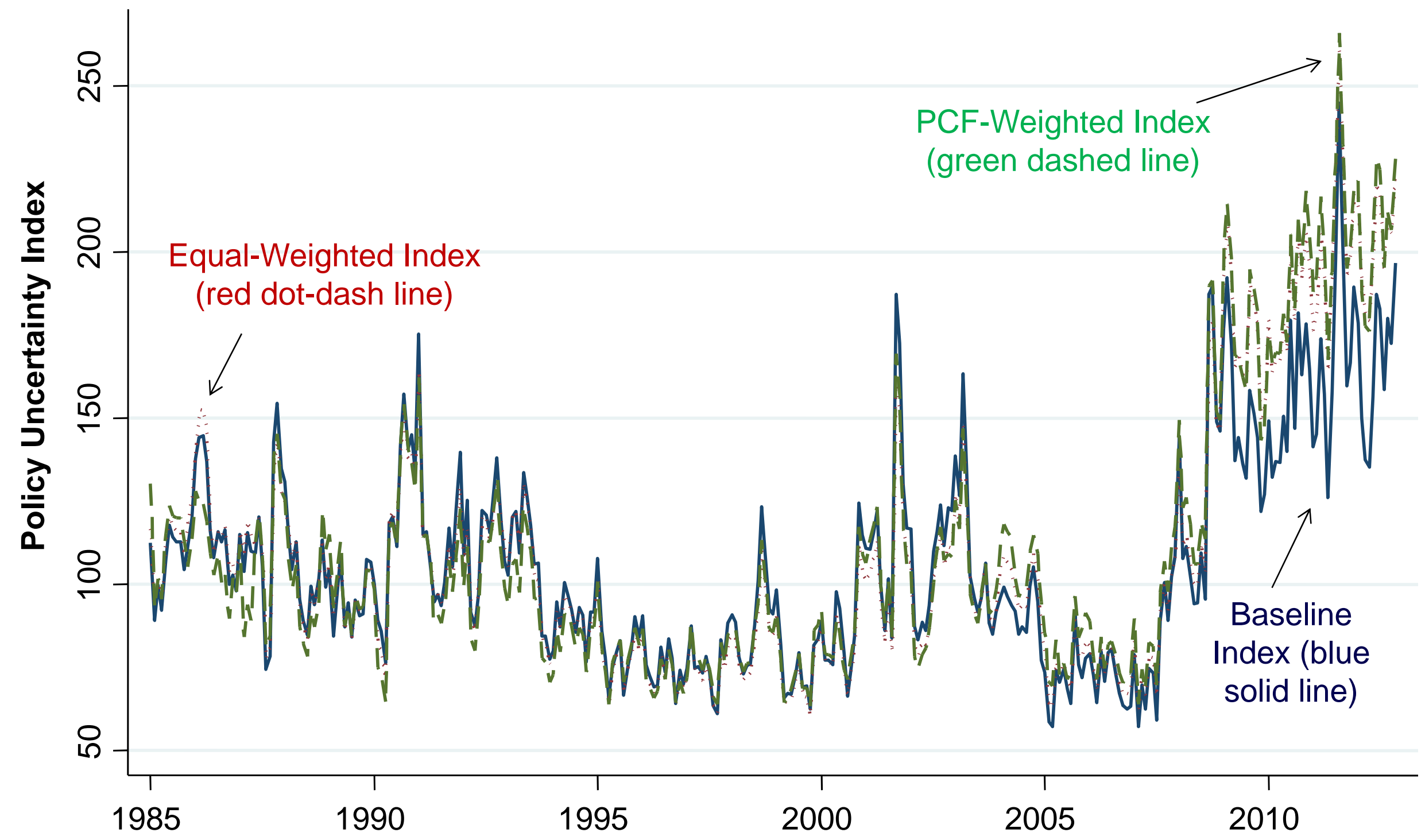

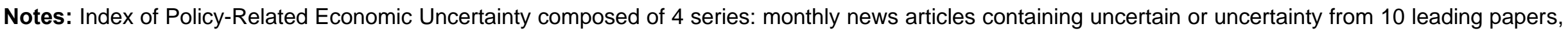

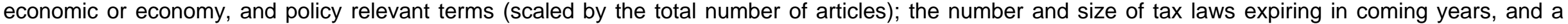

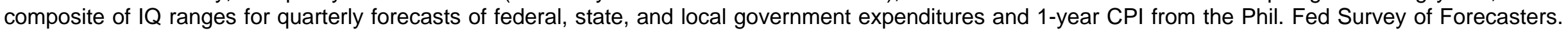

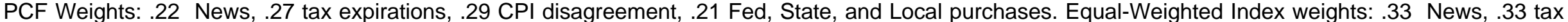

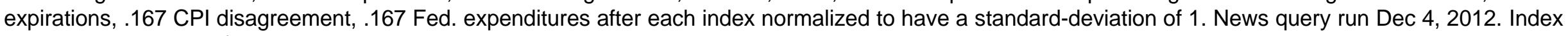
normalized mean 100 from 1985-2009. 
Appendix Figure A2: Long-run implied volatility has remained high (like EPU) since 2008 while short-run implied volatility has fallen

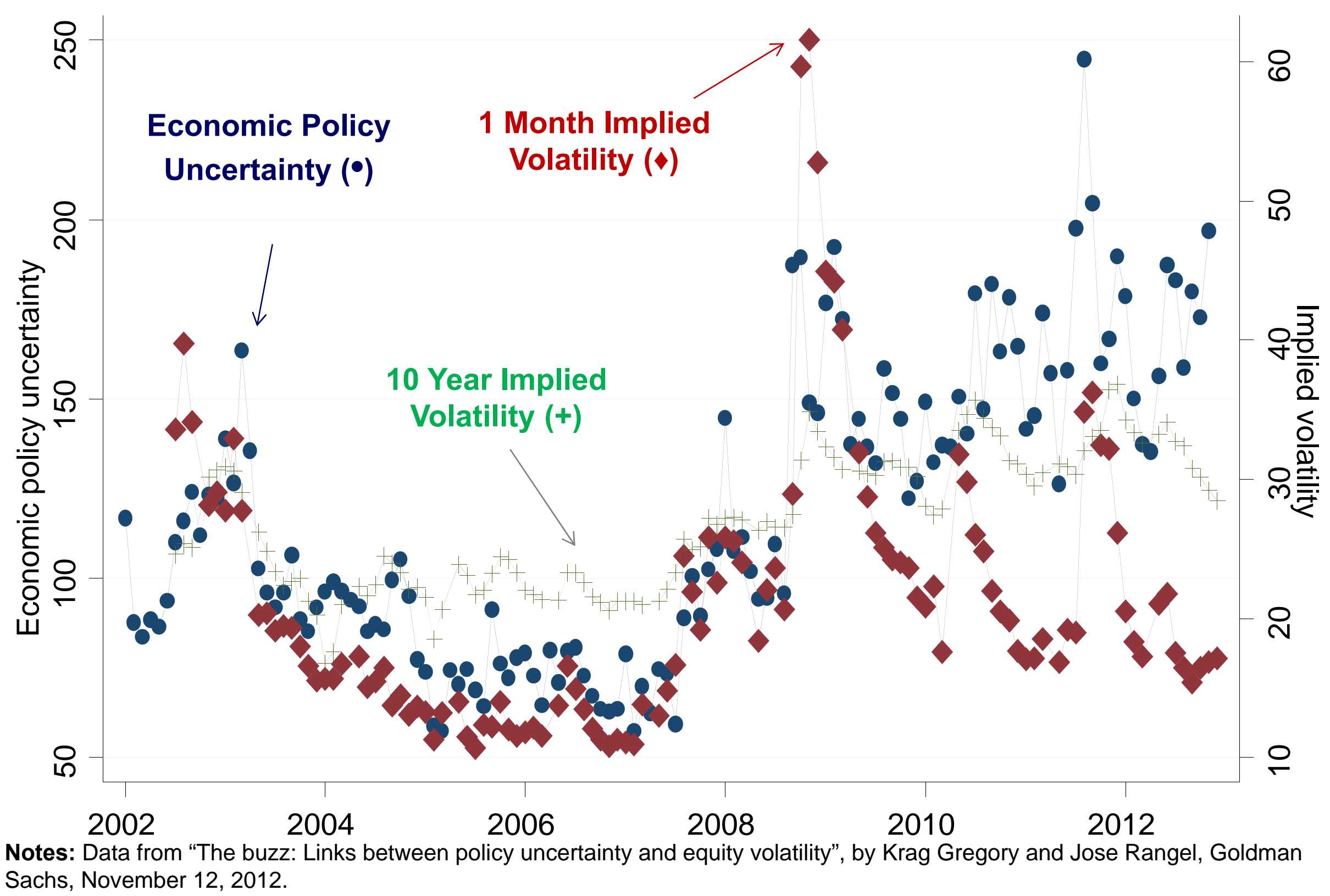

